\title{
LOS DOMINIOS Y PREBENDAS ECLESIÁSTICAS DE LA ALTA NOBLEZA EN GALICIA: LA HISTORIA DE UNA REINTEGRACIÓN FRUSTRADA
}

\author{
Por \\ MARÍA JESÚS BAZ VICENTE
}

Constatar que la alta nobleza gallega poseía a principios del siglo XIX prácticamente la mitad del señorío gallego ${ }^{1}$ obligaba a revisar una vieja teoría sobre la suerte de sus «derechos» en el tránsito a la Edad Moderna². Tal es el caso de los dominios y prebendas eclesiásticos usurpados en los siglos bajomedievales por las casas de Lemos, Andrade y Monterrei, los cuales, lejos de haber sido reintegrados a la Iglesia, fueron conservados en buena parte por aquellas hasta comienzos del siglo XX. La forma en que fue tratado el problema por los Reyes Católicos, los testimonios que prueban la continuidad de dichos bienes a manos de la nobleza, así como la instrumentalización social que sus titulares pudieron hacer de prebendas eclesiásticas, como el derecho de patronato, constituyen todos ellos el motivo de este trabajo.

\footnotetext{
' Eiras Roel, A., 1989, «El señorío gallego en cifras. Nómina y ranking de los señores jurisdiccionales», en Cuadernos de Estudios Gallegos, XXXVIII, p. 117.

${ }^{2}$ Véase al respecto, Baz Vicente, $\mathrm{M}^{\mathrm{a}} \mathrm{J}$., 1996, Señorí y propiedad foral de la alta nobleza en Galicia (siglos XVI-XX): la casa de Alba, Madrid, capítulos II y IV.

"CUADERNOS DE ESTUDIOS GALLEGOS", Tomo XLV, Fascículo 110, Santiago 1998.
} 


\section{1.- LA USURPACIÓN DE DOMINIOS Y PREBENDAS DE LA IGLESIA EN EL BAJO MEDIEVO}

Al entrar en la Baja Edad Media Galicia ya era una región fuertemente señorializada a manos de las instituciones eclesiásticas, las grandes beneficiarias de las mercedes regias en el siglo XII. En principio, una realidad de esas características dejaba escasas posibilidades de expansión a la nobleza de pequeños caballeros aupada por los Trastámara, pero la debilidad que seguía padeciendo la Corona, unido al poder que concedía su proyecto político al estamento nobiliario, sentarían las condiciones necesarias para que esa limitación de partida pudiera ser superada de forma efectiva.

El empleo de la fuerza fue el arma por excelencia de expansión de los dominios de los caballeros gallegos, auténticos promotores del clima de violencia privada que afectó a la Galicia bajomedieval y, muy en especial, a las instituciones eclesiásticas por las circunstancias ya aludidas ${ }^{3}$. De ello dan buena cuenta los abundantes testimonios que nos han quedado sobre el origen tan poco honroso de gran parte de estos dominios: excomuniones, reales pragmáticas, pleitos, y sobre todo los testamentos con sus típicos actos de arrepentimiento «ante mortem» dando orden de dejar libres los bienes ocupados por la fuerza o de recompensar por ello a las instituciones afectadas, tal y como dispusieron, entre otros, Gonzalo Ozores de Ulloa en favor del monasterio de Sobrado ${ }^{4}$, o D. Sancho Sánchez de Ulloa 5 .

Efectivamente, la nueva nobleza que se impone en Castilla en el Bajo Medievo medra a la sombra de las donaciones que logra arrancar a la monarquía de los Trastámara, que pese al plan de Enrique II no pudo

\footnotetext{
${ }^{3}$ Véase, García Oro, J., 1981, La nobleza en la Baja Edad Media. Iglesia, Señorio y Nobleza, Santiago.

${ }^{4}$ Transcrito en, A.L.F., 1931, «Año 1402. Testamento de Gonzalo Oçores de Ulloa, progenitor de los Condes de Monterrey», Galicia Histórica. Colección Diplomática.

De este caballero Vasco de Aponte, aludiendo a la frecuencia con la que recurrió a la violencia, afirma que se había hecho en A ulloa con todo lo que no era suyo (1986 ed., Recuento de las casas antiguas del reino de Galicia, Santiago, p. 162).

${ }^{5}$ Sus últimas voluntades (1505) son una auténtica sucesión de mandas compensatorias en favor de numerosas instituciones eclesiásticas: véase, Galicia Histórica. Colección Diplomática, doc. LXXVI.
}

"CUADERNOS DE ESTUDIOS GALLEGOS", Tomo XLV, Fascículo 110, Santiago 1998. 
superar la situación de debilidad crónica de la que ella misma había surgido. Ahora bien, es igualmente cierto que la ambigüedad de los términos en los que frecuentemente fueron redactados los albalaes reales pudo ser aprovechada por los caballeros para intensificar el ejercicio de su señorío, reivindicando unas prerrogativas que no les correspondían en derecho $^{6}$, así como para expandir su ámbito territorial sobre poblaciones que o bien conformaban los alfoces de villas y ciudades de realengo ${ }^{7}$, o bien pertenecían a la Iglesia. En este último caso, las relaciones que vinculaban a ambos colectivos y la instrumentalización de mecanismos jurídicamente reconocidos facilitaron si cabe aún más el asalto a sus señoríos.

La «encomienda» fue uno de los mecanismos más recurridos. Según han puesto reiteradamente de manifiesto los especialistas en el tema, proporcionó a los caballeros el instrumento y la coartada perfecta para hacerse con buena parte de la hacienda de las entidades eclesiásticas. Consistente en su origen en una relación benéfica entre dos partes libres sobre la base de un compromiso de protección, al igual que las behetrías vio como a lo largo del siglo XIV su función se iba desvirtuando bajo la presión expansionista de la nueva nobleza para convertirse en un mero instrumento de acrecentamiento de solares a costa de los dominios que presuntamente se iba a proteger. Impuesta cada vez más contra la voluntad de dichas instituciones, su precio - de ser el pequeño canon y servicios pactados en un inicio- pasó a consistir en la ocupación de aquellos dominios que pudieran resultar de interés al comendero, además de en extorsiones tributarias de todo tipo según se ha podido ver en los presupuestos de algunas casas ${ }^{8}$.

Este fenómeno parece haber tenido en Galicia una intensidad y una vigencia superiores a la de otros ámbitos de la Corona de Castilla. Las razones de ello estarían en la introversión que dominó en la nobleza gallega desde los siglos centrales de la Edad Media, así como en las opciones políticas tomadas en su momento por los parientes regios asentados en Galicia, y más concretamente por los titulares del condado de

\footnotetext{
${ }^{6}$ Baz Vicente, $M^{a}$ J., 1996, op. cit., pp. 75-124.

${ }^{7}$ Caso por ejemplo de Betanzos, según se menciona en el pleito sostenido por los jurisdiccionales de las Mariñas dos Condes en 1490: exp. 9392, fol 120, AHRG.

${ }^{8}$ García Oro, J., 1977, op. cit., pp. 119-120.
}

"CUADERNOS DE ESTUDIOS GALLEGOS", Tomo XLV, Fascículo 110, Santiago 1998. 
Trastámara y estados de Lemos: D. Pedro Enríquez, Condestable de Castilla, y su hijo D. Fadrique Castilla Castro, duque de Arjona ${ }^{9}$.

D. Pedro Enríquez, pese haber sido agraciado en cuanto sobrino de Enrique II con el Condado de Trastámara, militó posteriormente en el bando rebelde al rey Juan I. El perdón real le evitó ser despojado de su casa. Pero entonces, recluido en sus estados de Lemos y decidido a hacerse con el control de Galicia, se lanzó a la formación de una amplia clientela de caballeros para cuyo sostenimiento y premio promocionó una intensa campaña de extorsión sobre los bienes y rentas de la iglesia. El poder y control por él alcanzados fueron tales que el rey Enrique III se abstuvo de intervenir en Galicia, especialmente en todo lo relacionado al clima de violencia y anarquía impuesta bajo sus directrices. Sólo tras su muerte, y aprovechando la vacante de la sede de Santiago, tomó cartas en el asunto nombrando como arzobispo a la persona de D. Lope de Mendoza $^{10}$.

La táctica seguida desde la iglesia de Santiago no fue, sin embargo, más allá del intento de alcanzar un compromiso de buen entendimiento y no beligerancia con los caballeros protagonistas de tales atropellos. Más aún, se emplearon métodos que en principio estaban en contradicción con el objetivo que se perseguía en última instancia, restituir y asegurar la integridad de la hacienda de las diversas instituciones eclesiásticas. La absolución de las censuras en las que habían incurrido muchos de estos caballeros, como es el caso de Gonzalo Ozores de Ulloa con motivo de la ocupación de la Tierra de Grobas -cuya posesión se le confirmó-, la cesión de toda clase de beneficios ${ }^{11}$, o incluso la puesta en práctica de una hábil política matrimonial ${ }^{12}$, son algunas de las estrategias empleadas con el objetivo de plegar a estos caballeros a su política y cometidos.

\footnotetext{
${ }^{9}$ Mitre Fernández, E., 1968, Evolución de la nobleza en Castilla bajo Enrique III, Valladolid, p. 65; García Oro, J., 1977, op. cit.

${ }^{10}$ Mitre Fernández, E., 1968, op. cit., p. 121.

"Es el caso del hijo homónimo de Gonzalo Ozores de Ulloa, que ganó por esta vía de manos del arzobispo de Santiago las feligresías de Roade, Nogueira, Pusada, Gendelle y Boimorto.

${ }^{12}$ La boda por ejemplo de Payo Gómez de Sotomayor con una sobrina del Arzobispo de Santiago se enmarcaría según E. Mitre Fernández dentro de esa política de D. Lope de Mendoza. Véase nota 34.
}

"CUADERNOS DE ESTUDIOS GALLEGOS", Tomo XLV, Fascículo 110, Santiago 1998. 
No se trata de minusvalorar el esfuerzo desarrollado por parte del arzobispo de Santiago, pero lo que no se puede negar es que el proyecto concebido por él y su rey no fue más allá de poner remedios pasajeros a problemas de orden estructural. Nada se hizo en relación a las circunstancias y relaciones político-sociales que generaban esa dinámica, así que la tregua alcanzada a fuerza de tantas concesiones debió de surtir escasos y fugaces resultados. El uso privado de la fuerza, lejos de remitir, continuó agravándose de forma alarmante en el siglo XV. Y es que, como señaló J. García Oro, estos linajes estaban embarcados para entonces en la lucha final por imponer sus respectivas tutelas locales. Por otra parte, contaban a su favor con la tendencia de los nuevos tiempos a considerar como hereditario todo cargo y beneficio. Con la encomienda asimilada a un vínculo a perpetuidad, ya nada podría impedir que las familias de comenderos consolidaran en su poder los bienes ocupados a la Iglesia ${ }^{13}$. La reiteración de las quejas de la iglesia y de la intervención regia, que precisamente llevó a López Ferreiro a afirmar que prácticamente «los documentos históricos que más abundan en Galicia son las provisiones de los reyes en que mandan que tales o cuales caballeros dejen los cotos y haciendas que tenían usurpadas a este $u$ otro monasterio» ${ }^{14}$, si algo pone de manifiesto es justamente la ineficacia de las medidas legales arbitradas por la corona para restablecer el estado primigenio de las posesiones de la Iglesia ${ }^{15}$. Todavía en 1466, Paulo II denunciaba en su bula de 5 de enero que los

${ }^{13}$ Los Moscoso, condes de Altamira se consolidaron como comenderos de los monasterios de Acibeiro, Baíñas, Camanzo, Moraime y Orria; los Ulloa, de los monasterios de Sobrado, Toques, Ferreira de Pallares y Vilar de Donas; y los Andrade, de los de Caaveiro, Meira, Monfero y Cinis: véase, López Ferreiro, 1986 ed., op. cit., p. 312.

${ }_{14}$ «El eco de la Verdad», Compostellanum, $\mathrm{n}^{\circ}$ 5, p. 196.

${ }^{15}$ La casa de Andrade es otro de los ejemplos más ilustrativos de esa trayectoria. A pesar de las órdenes reales para que sus titulares devolvieran diversos territorios tomados por la fuerza, éstos lograron consolidarlos en su poder accediendo como mucho a reconocer el dominio superior de las instituciones eclesiásticas con el pago consiguiente de un feudo o canon foral absolutamente simbólico, tal y como ocurrió con las tierras de Nogueirosa tomadas al monasterio de Sobrado. En otros casos ni siquiera accedieron a ello, caso por ejẹplo de la villa y tierra de A Graña, junto con la granja de Reparada y puerto de Prioiro en la tierra de Ferrol, por cuyo motivo siguen enfrentados aún en el siglo XVIII. En esos tiempos ni siquiera la pena de la excomunión pudo conseguir que estos señores, como otros muchos, se alzaran con la propiedad de algunas de sus usurpaciones, caso por ejemplo de los cotos de Muniferral y Feás, tomados al Cabildo de 
excesos anatemizados por sus predecesores seguían vigentes con tanta o mayor intensidad sobre los bienes de los monasterios y rentas de las iglesias de Galicia, la mayor parte de las cuales se hallaban abandonadas y desiertas por ese motivo ${ }^{16}$.

Esto nos lleva a enlazar con otro aspecto del tema, la usurpación de los derechos de patronato de las iglesias. El mapa de patronatos y sincuras de Lemos, Andrade y Monterrei, aunque con limitaciones lógicas, entre otras razones por el carácter tardío de estos dominios, responde a la distribución «grosso modo» de sus señoríos ${ }^{17}$. Su origen, no obstante, no parece que esté por norma general en las vías ortodoxas reconocidas por el derecho canónico -fundación, edificación, o dotación de una nueva iglesia. Aunque es conocido el afán del que dio muestras el que fue el primer señor de Andrade por fundar nuevas iglesias ${ }^{18}$, el avanzado estado de ocupación poblacional de Galicia y la presencia ya notable que la Iglesia había alcanzado en el rural no dejaban demasiadas posibilidades para avanzar por esa vía. Por su parte, las donaciones papales y regias en favor de los caballeros no parece que fueran tan numerosas. Pese a que en algunas ocasiones los señores pretendieron hacer valer sus títulos de patronos por supuestas donaciones papales, lo cierto es que son muy pocos los casos conocidos, y más aún los probados, tratándose generalmente además de concesiones de la Edad Moderna. Ese es el caso, por ejemplo, de los beneficios de Centroña, Porto y Vilar, concedidos por León X al Conde de Andrade ${ }^{19}$.

Santiago. Véase, Vaamonde Lores, 1909, Ferrol y Pontedeume, A Coruña, pp. 4-5; López Ferreiro, A., 1898-1911, Historia de la S.A.M.I. de Santiago de Compostela, vol. VII, pp. 22-23; vol. VIII, p. 194.

${ }^{16}$ «La culpa era de los señores y caballeros que á título de patronos, o descendientes de los fundadores se habían apoderado de todas las rentas y emolumentos. Algunos hasta invocaban en su favor concesiones pontificias»: López Ferreiro, A., 1986, op. cit., p. 306.

${ }^{17}$ Véase apéndice.

${ }^{18}$ Véase, Rodríguez Galdo, $\mathrm{M}^{\mathrm{a}}$ X., 1976, Señores y Campesinos en Galicia, siglos XIV-XVI, Santiago, p. 204.

${ }^{19}$ Véase Vaamonde Lores, C., 1917, Gómez Pérez das Mariñas y sus descendientes, A Coruña, p. 82.

"CUADERNOS DE ESTUDIOS GALLEGOS", Tomo XLV, Fascículo 110, Santiago 1998. 
Por lo que respecta a las donaciones regias, hay que decir que en los documentos de concesión de señoríos otorgados a los fundadores de estas casas para nada se menciona la cesión del patronato real sobre las iglesias. Unicamente en la donación que Fernando IV hace del coto de Augas Santas a Sancho Sánchez de Ulloa en 1310 pudiera presuponerse la inclusión de tales beneficios por cuanto al enumerar sus poblaciones se las refiere con el término de «iglesias» ${ }^{20}$.

Todo hace pensar, por lo tanto, que en su gran mayoría estos patronatos serían fruto de la situación de fuerza y violencia creada por esos mismos señores, incluso en aquellas ocasiones en las que la transferencia de la totalidad del beneficio reviste visos de legalidad en forma de cesión foral o de donación episcopal, ésta última deslegitimada de forma definitiva por Trento ${ }^{21}$. Una prueba más de ello la tenemos en la frecuencia con la que los caballeros gallegos ordenaron en sus últimas voluntades el desembargo de parte de las sincuras que tenían tomadas por la fuerza a iglesias y monasterios ${ }^{22}$, y sobre todo en el hecho de que este tipo de peticiones raramente surtían efecto. Así ocurrió, por ejemplo, con las sincuras que la casa de Monterrei tenía ocupadas al monasterio de Vilar de Donas. Antas de Ulla y Ligonde, entre otras, habían sido usurpadas en su día por Gonzalo Ozores de Ulloa. A su muerte, su hijo y sucesor, Lope Sánchez de Ulloa, pese a reconocer que eran del Monasterio, se negó a devolverlas y tomó posesión de las mismas. Sólo poco antes de morir, y ante el hecho de su excomunión, accedió a negociar su devolución, pero de nuevo su viuda, Dña Inés de Castro, volvería a ocuparlas violentamente para pasarlas a su hijo y sucesor, D. Sancho Sánchez de Ulloa. La Real Pragmática de Juan II obligó a éste a restituir al monasterio dichas sincuras, pero siguiendo con la pauta de comportamiento propio de este sector, tan sólo un año después volvió a ocuparlas ${ }^{23}$.

\footnotetext{
${ }^{20}$ Exp. 28.138, pieza $58 \mathrm{n}^{\circ} 30, \mathrm{AHN}$

${ }^{21}$ Véase, Garrote Martín, A., 1921, El derecho de patronato, Lugo, p. 40.

${ }^{22}$ En el testamento de Gómez Pérez das Mariñas, por poner un ejemplo, se ordena reintegrar a sus legítimos titulares hasta un total de 11 sincuras. Véase, Vaamonde Lores, C., 1917, op. cit., p. 18.

${ }^{23}$ Véase, Novo Cazón, J.L., 1986, El priorato Santiaguista de Vilar de Donas en la Edad Media (1194-1500), A Coruña, p. 143.
}

"CUADERNOS DE ESTUDIOS GALLEGOS", Tomo XLV, Fascículo 110, Santiago 1998. 
Para entender el interés que demostraron los señores también por este tipo de prebendas hay que tener en cuenta que el derecho de patronato conllevaba, junto a los derechos honoríficos y a la «devotio» siempre referidos ${ }^{24}$, también un beneficio material directo. Al pretender gozar los señores, por esa su condición, de un derecho eminente sobre el conjunto de las tierras, exigieron igualmente hacer del derecho de patronato una consecuencia del señorío y, así, participar en los frutos que el curato pudiera producir: los diezmos de rigor, incluyendo a veces las primicias, así como una parte, fija o incluso proporcional, de las rentas procedentes de la explotación de las tierras del iglesario, tal y como ocurría en los dominios de las Mariñas de los Andrade, en las que se llegó incluso a repartir proporcionalmente las tierras del iglesiario entre el curato y el señor patrono.

A ese beneficio material directo se une una no menos importante utilidad social. La condición de patrono de una iglesia conllevaba el derecho de presentación de los curas que la ocuparían, lo que suponía que los señores podían dotarse de clérigos afectos a los intereses y exigencias de sus casas. Si además tenemos en cuenta, por un lado, la resistencia que éstas generaban entre los vasallos y, por el otro, el papel clave que el clero rural desempeñaba en el control de las voluntades y mentalidades de la masa popular, no se podrá entonces negar el atractivo que ese título tuvo que ejercer sobre los señores, sobre todo después de experiencias como la de las revueltas hirmandiñas, en las que el clero parroquial jugó un papel de primer orden como apoyo psicológico y material de la ruralía levantada. Desde ese punto de vista, parece algo más que una casualidad el trasvase de beneficios que se produjo justo tras la revuelta hirmandiña en favor por lo menos de algunos de los señores más castigados por el alzamiento.

Entre otros, parece participar de esa reacción y deseo de agregar la autoridad eclesiástica al señorío secular el entonces señor de Andrade, al que vemos actuando en esa dirección justamente en la comarca de Ferrol, conocida por su resistencia histórica contra esta casa. Siendo el monasterio de Xubia el titular de gran parte del patronato de las iglesias de la

\footnotetext{
${ }^{24}$ Cfr., Garrote Martín, A., op. cit.
} 
zona, el de Andrade se hizo pagar, tras la revuelta hirmandiña, las supuestas honras y mercedes rendidas por los fundadores de su casa nada menos que con un «foro» de un total de veinte patronatos, además de ciertos casares; foro que, por otra parte, parece más una renuncia que otra cosa teniendo en cuenta lo ridículo de la pensión, $400 \mathrm{mrs}$., y la ambigüedad del alcance cronológico del mismo, «para él y los descendientes de la casa de Andrade» ${ }^{25}$. Por su parte, resulta también muy significativo que el otro gran perseguido por los Hirmandiños, el Conde de Lemos, lograra hacerse en los años posteriores con sendas autorizaciones del obispo de Lugo y del provisor de Ourense para que cualquier persona pudiera renunciar en su favor al disfrute de patronatos eclesiásticos o legos, y que a su amparo lograra hacerse con patronatos como el de San Paio de Abeleda, en un marco donde los desafueros de la casa habían provocado una fuerte conflictividad $^{26}$.

\section{2.- LA RECONSTRUCCIÓN DE LOS DOMINIOS DE LA IGLE- SIA EN LA EDAD MODERNA: UNA OPERACIÓN FRUSTRADA}

Con la llegada de los Reyes Católicos al poder uno de los problemas más serios con los que hubo de enfrentarse la nobleza bajomedieval fue la exigencia de las instituciones eclesiásticas para que les fuera restituido todo lo a ellas usurpado. La especial atención que los monarcas prestaron a este problema así como la decisión con la que en un principio actuaron no parecía augurar nada bueno. La misma decisión de sentar su Monarquía sobre la base de la disciplina, del orden y de la obediencia a la autoridad pública superior, erigida ya en único garante válido de la integridad de bienes y personas, era una sentencia de muerte para todas aquellas

\footnotetext{
${ }^{25}$ Son las sincuras de S. X. de Ferrol, Serantes, Brión, Doniños, Esmelle, Maniños, Cobas, Vilar, Cerdido, S. Xurxo de Moeche, Ferreira, Sillobre, Maniños, Grandal, Perbes, Andrade, Narón, Franza, y San Mateo. Véase, Vicetto, B., 1872, Historia de Galicia, t. VI, pp. 127-128.

${ }^{26}$ Según un documento conservado en el archivo de los Duques de Alba, fue por esa vía por la que los condes de Lemos se hicieron con el patronato del coto de San Paio de Abeleda, en tierra de Caldelas: Lemos, 179-8, ADA.
}

"CUADERNOS DE ESTUDIOS GALLEGOS", Tomo XLV, Fascículo 110, Santiago 1998. 
posesiones disfrutadas en concepto de encomienda. Puesto que los hombres del reino eran desde entonces súbditos del rey, antes que vasallos de sus señores, era a la Corona a la que correspondía en lo sucesivo su protección.

Conscientes los RRCC del desorden endémico al que conducía la primacía de la «fidelidad individual» sobre la obediencia y el bien públicos, y conocedores de los abusos que se escondían detrás de las encomiendas, proclaman que «de las dychas vyllas e lugares e vasallos e rentas e vienes nos avemos de ser comenderos y los tener y defender ${ }^{27}$. En conformidad con ello, establecen por las provisiones de 31 de marzo de 1483 y de 5 de octubre de 1486 que los señores gallegos no podían seguir teniendo vasallos en encomienda, ni siquiera con el consentimiento de los encomendados, y que en un plazo de tres meses tendrían que devolver a sus legítimos titulares los dominios que detentaran en ese concepto.

Con todo, la nobleza gallega no se dejó amedrentar a juzgar por las órdenes sucesivas que sobre esa misma cuestión se repitieron en los años posteriores. Si en 1487 Gobernador y Alcalde Mayor de Galicia recibían la orden de asegurar al monasterio de Celanova frente a las usurpaciones del Conde de Ribadavia y de hacer efectiva la devolución de ciertas posesiones $^{28}$, todavía en 1523 Carlos V ordenaba que ningún castillo llevase bienes eclesiásticos en encomienda ${ }^{29}$. Como en su día reconoció J. García Oro, al no haber ido acompañadas las órdenes reales de las medidas expeditivas necesarias para garantizar la debida ejecución de la voluntad regia, a la Iglesia no le quedaría al final más alternativa que el recurso a la justicia ordinaria, mucho más lento y de resultados inciertos teniendo en cuenta la influencia y consiguiente capacidad de resistencia de la nobleza, algunos de cuyos miembros no dudaron incluso en falsificar los documentos ${ }^{30}$.

\footnotetext{
${ }^{27}$ Fernández Vega, L., 1982, La Real Audiencia de Galicia como órgano de gobierno durante el Antiguo Régimen, 1480-1808, A Coruña, p. 203.

${ }^{28}$ García Oro, J., 1969, «Los señoríos monásticos gallegos en la Baja Edad Media. Documentos sobre su evolución», Compostellanum, XIV, 4, p. 575.

${ }^{29}$ Colombás, G.M., 1980, 1980, Las señoras de San Paio, Santiago, p. 83.

${ }^{30}$ El II Conde de Camiña fue sentenciado precisamente por haber hecho varias escrituras falsas a su favor. Véase, Murguía, M., 1882, Estudio sobre la propiedad territorial de Galicia. El Foro. Sus orígenes, su historia y sus condiciones, Madrid, p. 184, nota 2.
}

"CUADERNOS DE ESTUDIOS GALLEGOS", Tomo XLV, Fascículo 110, Santiago 1998. 
La reivindicación de la titularidad de cotos y señoríos, así como de competencias públicas y regalías concretas cuando se trataba de dominios compartidos, es una constante en los expedientes judiciales a los que hubieron de hacer frente las casas de Lemos, Andrade y Monterrei en el tribunal de la Real Audiencia de Galicia. Significativamente, la mayoría de los demandantes son entidades eclesiásticas. La casa de Andrade, por ejemplo, aparece enfrentada por esos motivos en el siglo XVI a los monasterios de Sobrado y de Caaveiro, y en el siglo XVII a los de Santo Domingo de A Coruña y a San Martín de Santiago. Por lo que se refiere a Lemos, las entidades demandantes son los monasterios de Montederramo y Sobrado, el Hospital de Santiago, el Cabildo de Mondoñedo, el Comendador de Quiroga y Portomarín, y la abadía de San Paio de Abeleda. En la casa de Monterrei, por último, aunque son también frecuentes los enfrentamientos con otros señores nobles de la zona y con villas del peso de Ribadavia o Allariz, la primacía sigue teniéndola la Iglesia. Las entidades que reclamaron con mayor frecuencia contra los titulares de esta casa son los monasterios de Celanova, Melón, Melide y San Martín Pinario; los conventos de Santa Clara de Allariz y de San Paio de Antealtares; y el arzobispado de Santiago.

A pesar de la animosidad combativa de la que dieron muestras sobradas las instituciones eclesiásticas, tal y como pudo entrever G.M. Colombás en su estudio sobre el convento de San Paio de Antealtares ${ }^{31}$, los viejos comenderos siguieron gozando en la Edad Moderna de vastos dominios procedentes de la Iglesia a cambio del pago de pensiones puramente simbólicas. Las casas objeto del presente estudio mantuvieron en su poder hasta el final del Antiguo Régimen importantes unidades territoriales arrancadas en situaciones de fuerza. Entre otras, habría que mencionar por su entidad, el señorío de Cambados, que los condes de Monterrei venían disfrutando en la condición de feudo a modo de foro de los comendadores de la Orden del Santo Sepulcro; el coto cerrado de Peibás y Casa Naia, aforado también con su jurisdicción y pechos en tan sólo 1.000 maravedís por el obispo D. Juan Fernández de Valdivieso al VIII Conde de Lemos,

${ }^{31}$ Colombás, G.M., op. cit., p. 83. Véase también: González Fernández, J.M., 1986, «Una aproximación a diversos aspectos de la justicia señorial en la Galicia del Antiguo Régimen» en Revista del Instituto José Cornide de Estudios .Coruñeses, 22.

"CUADERNOS DE ESTUDIOS GALLEGOS", Tomo XLV, Fascículo 110, Santiago 1998. 
D. Francisco Fernández de Castro, todavía en $1640^{32}$; y las jurisdicciones de Deza y Aveancos ${ }^{33}$, que logran mantener en su poder una vez que el arzobispo de Santiago, cansado ya de pleitos inacabables y costosos, decide avenirse a que don Fernando Ruiz de Castro permaneciese en la posesión de dichas tierras, cediéndoselo para ello en feudo, por cuyo reconocimiento tendría aquel que pagar una hacanea al año:

${ }^{32}$ Noticia sacada de una referencia que a ese documento se hace en una relación de papeles de la época de la marquesa de Aytona viuda de Lemos ya en el XVIII: legajo 3, $\mathrm{n}^{\circ} 22$, Caja 5265, AHRCM.

${ }^{33} \mathrm{La}$ incorporación de estas tierras a los dominios de los Ulloa parece haberse efectuado como consecuencia de los lazos de clientela y de los deudos que con los Ulloa tenían establecidos otros caballeros, en este caso en concreto Pedro Vazquez de Insua, el mismo que tomó por la fuerza dichas tierras. La versión tradicional sostiene que estos dominios se habrían consolidado en poder de los Ulloa gracias simplemente a una hábil política matrimonial: concretamente a raíz de la boda de D. Lope Sánchez de Ulloa con la sobrina del arzobispo Mendoza, Dña Leonor de Mendoza (Vasco de Aponte, 1986 ed., Recuento de las casas antiguas del Reino de Galicia, Santiago, pp. 130, 166, 178). El problema está en que en ocasiones el manuscrito de Vasco de Aponte identifica a esa sobrina también como Dña Mayor, y en que efectivamente existía una sobrina así llamada pero casada con Payo Gómez de Sotomayor. Los nuevos documentos que hemos podido localizar parecen indicar que esa versión tradicional se habría forjado sobre la confusión de dos o tres mujeres diferentes por causa de la existencia de dos donaciones distintas del dicho feudo (1410 y 1445) así como de una infeliz transposición de nombres y de apellidos: Dña Leonor de Mendoza, hija de Juan de Mendoza, primera mujer de Lope Sánchez y madre del mismo Vasco López que por vía matrimonial se hace con los dominios de los Moscoso; Dña Mayor de Mendoza, hija de Fernán Yáñez de Mendoza, mujer de Payo Gómez de Sotomayor; y Leonor de Sotomayor, hija de Dña Mayor de Mendoza. Las donaciones hechas por el arzobispo en ningún caso fueron a favor de la misma Dña Leonor casada con el titular de los Ulloa, D. Lope Sánchez de Ulloa: la donación de 1410 se hizo a favor de la mujer de D. Payo Gómez de Sotomayor, lo cual tendría hasta cierto punto lógica teniendo en cuenta la política del Mendoza y que dichas tierras habían sido ocupadas por vía de feudo por un tal Alvar Rodríguez de Sotomayor según se menciona en la donación de 1445; por su parte, la segunda donación se hizo a favor de Dña Leonor de Sotomayor, mujer que fue del mismo caballero Pedro Vazquez de Insua que según el testimonio de esta escritura había ocupado por la fuerza dichas tierras. Estas pasan a la casa de los Ulloa solamente cuatro años después (1449), cuando Dña Leonor de Sotomayor cede ese feudo a D. Lópe Sánchez de Ulloa siendo ya esposa del caballero Díaz Cadórniga. Todo parece indicar, pues, que fue la muerte entre tanto del que había sido el primer esposo de Dña Leonor de Sotomayor lo que determinaría esa reversión al linaje de los Ulloa, pues en sus mandas testamentarias el caballero Pero Vazques da Insua dispone que se dieran sus «coutos de Aveancos» a Lopo Sánchez de Ulloa. Fuente: Exp. 28138, pz. 56 y 57, nº 29, AHN.

"CUADERNOS DE ESTUDIOS GALLEGOS", Tomo XLV, Fascículo 110, Santiago 1998. 
«... por evitar pleytos fastidios gastos y otras dificultades y por lo que toca al descargo de mi conciencia y a la autoridad y acrecentamiento de la nuestra Santa Iglesia (...) tuvimos por bien de concertarnos con el Illsmo. señor Don Fernando Ruiz de Castro Marqués de Sarria (...) en los pleytos que con su Sria. teníamos pendientes en el Consejo Real como en la Chancillería de Valladolid y la Audiencia Real de Galizia sobre las tierras de Deça y Aveancos (...) conservando y manteniendo al dho señor Marqués en la possesión que de las dhas tierras tiene Sin darle impedimentos ni Molestia alguna sino que libremente dexeys usar sus officios e todos e qualesquier juezes merinos y escrivanos que el dho Señor Marqués en las tierras de Deça y Aveancos nombrare (...) assi mesmo a vos el dho nro. provisor que Recibays el feudo que el dicho Señor Marqués nos es obligado dar por Raiz del dho concierto» ${ }^{34}$.

Las reivindicaciones de la Iglesia en materia de usurpación y encomiendas, por lo tanto, no terminaron con demasiada frecuencia de la mejor manera para sus intereses. Incluso cuando la justicia dictaminó en su favor, estos señores lograron forzar soluciones de compromiso que les permitirían mantener en su poder de forma ya definitiva los bienes usurpados. De hecho, cotos que en un principio habían sido dados en encomienda aparecen en el siglo XVI en las manos de los mismos señores en calidad de feudos o de foros, instrumentos estos de los que se valieron los señores, no sin resistencias por parte de la Iglesia, para poder mantenerse en el disfrute de esos dominios sin «ir contra derecho». En el expediente del pleito sostenido por el monasterio de Sobrado con la casa de Monterrei por la Granja de Fente y el Couto de Vilouriz se dice, aludiendo a la «encomienda» detentada en el pasado por los Ulloa sobre esas tierras, que con esa «Voz se expresaban en aquel tiempo los foros de maior consequencia», lo que viene a corroborar que efectivamente las viejas encomiendas se perpetuaron en foros ${ }^{35}$. No es casual, de hecho, que la

\footnotetext{
${ }^{34}$ «Provisión del Cardenal Fr. Juan de Toledo Arzobispo de Santiago acerca del concierto con D. Hernando Ruiz de Castro, Marqués de Sarria, Señor de las Casas de Andrade Y Ulloa»: ADA, Lemos, 34315.

${ }^{35}$ Fuente: Exp. 164/18, AHRG.
}

"CUADERNOS DE ESTUDIOS GALLEGOS", Tomo XLV, Fascículo 110, Santiago 1998. 
concesión ya en calidad de «foro» que se hizo de esas tierras a Fernando de Andrade -como marido de Dña Francisca de Zúñiga- en 1509 se realizara todavía a «pleito y condición» de que el conde y sus descendientes «fueran obligados de nos defender y amparar defenderedes y amparedes (...) de todas fuerzas y violencias e daños...». Finalmente, resulta igualmente elocuente la descripción que a comienzos del siglo XVII hace don Gerónimo del Hoyo de los dominios de San Martín Pinario, cuando señala que tiene «aforados» muchos de sus dominios y jurisdicciones a los primeros señores de Galicia, que pagan en su reconocimiento «feudos y otros tributos».

«Este real monasterio solía tener innumerables cotos, jurisdicciones y tierras y muchas dellas tiene aforadas a los mejores de este Reyno, como son a los condes de Lemos, de Altamira, de Monterrey y otros muchos caballeros y personas particulares de los quales y en su recoconoscimiento pagan al dicho monasterio feudos y otros tributos $y$ además de los que tiene aforados y otros que ha dexado perder y le traien enaxenados, tiene al presente al pie de sesenta cotos... $\rangle^{36}$.

Hay que tener en cuenta, para poder entender esa capacidad de resistencia, que los señores habían logrado ir asimilando sus encomiendas a feudos y foros ya con anterioridad ${ }^{37}$. La absoluta y crónica incapacidad de la Iglesia para hacer frente de forma eficaz a los desmanes y ambiciones de la nobleza les había llevado a acceder a unos acuerdos de transacción por los que las familias comenderas consolidaban en su poder los bienes usurpados a cambio del reconocimiento del dominio superior de sus legítimos titulares. En tales ocasiones, efectivamente, la Iglesia veía reconocida su titularidad superior sobre la posesión usurpada. Pero ello no pasaba de ser, en realidad, un gesto simbólico sin mayor trascendencia en cuanto al ejercicio efectivo de su legítimo dominio señorial. Eran los señores quienes, en definitiva, iban a poder explotar de forma efectiva

\footnotetext{
${ }^{36}$ Gerónimo del Hoyo, 1607, Memorias del Arzobispo de Santiago, Santiago, p. 61.

${ }^{37}$ Una breve aunque sustanciosa alusión a este tema la hace M. Murguía en su obra ya citada (1882), pp. 171, 174. Véase también, García Oro, J., 1969, «Los señoríos monásticos gallegos en la Baja Edad Media», en COMPOSTELLANUM, XIV.
}

"CUADERNOS DE ESTUDIOS GALLEGOS", Tomo XLV, Fascículo 110, Santiago 1998. 
dichas posesiones, y ello a cambio tan sólo de un reconocimiento formal de vasallaje, plasmado en la entrega simbólica de unas hacaneas en el caso concreto de los feudatarios del arzobispado de Santiago ${ }^{38}$.

A ello hay que añadir la confusión entre dominios eclesiásticos y nobiliarios producida con ocasión de la ocupación de los altos cargos eclesiásticos por miembros de los mismos linajes que actuaban de comenderos, tal y como ocurrió en las sedes de Lugo y Mondoñedo con los titulares de los estados de Lemos ${ }^{39}$; las vinculaciones y dependencias de todo tipo existentes entre ambas partes; y por último, lo vicioso de las formas procesales de la Edad Moderna así como el marcado conservadurismo/legalismo de la Corona, no dispuesta nunca a soluciones drásticas $\mathrm{y}$, mucho menos aún, a poner en peligro el pacto con la nobleza sobre el que se había establecido la nueva monarquía.

En cuanto a los foros propiamente dichos, la trayectoria no fue muy distinta. Fue frecuente que los señores se negaran a pagar la renta en su día fijada, o a restituir los bienes al directo dominio una vez que finalizaban las vidas estipuladas, pretendiendo en tales ocasiones alzarse con la plena propiedad. Aunque a través de la justicia pudo forzarse el reconocimiento del dominio directo de la Iglesia, e incluso cierta actualización de las rentas, lo cierto es que con frecuencia su ejecución no fue posible, al menos en los términos absolutos que preveía la condena judicial restitutoria, logrando forzar de nuevo al amparo de los compromisos creados entre ambas partes concordias siempre favorables a los intereses de estas casas.

El conflicto que los titulares de Lemos sostuvieron en el siglo XVI con el monasterio de S. Salvador de Lourenzá es un ejemplo paradigmático, entre otros muchos, de lo que acabamos de comentar. En 1597-98 el

\footnotetext{
${ }^{38}$ En ocasiones el reconocimiento del dominio superior por la vía de del feudo o del foro conllevaba la condición de que el canon a pagar sería estipulado por el propio comendero. Eso fue lo que ocurrió con las tierras de Noguerosa que los Andrade había usurpado al monasterio de Sobrado en la comarca del Eume: apesar de la real carta de Juan I en 1380 obligando a sus titulares a desembargar dichos bienes, la casa logró mantener en su poder la parte más sustanciosa a pesar de las reclamaciones del monasterio, por lo que éste acabaría optando a dicho acuerdo; el canon fijado por el señor de Andrade sería de 17 insignificantes maravedís. Véase, Vaamonde Lores, A., 1909, Ferrol y Puentedeume, A Coruña, p. 42.

${ }^{39}$ Véase nota 47.
} 
entonces conde de Lemos intentó alzarse con la propiedad de una serie de patronatos en la comarca de Ferrol que en realidad llevaba por un foro del Priorato de Xuvia de 1472, renovado en 1541. La demanda de Lemos fue desestimada primero en la Real Audiencia y después en la apelación hecha a la Chancillería de Valladolid. Pero no así la súplica que elevó contra esa segunda sentencia, logrando forzar por esa causa una concordia el 18 de octubre de 1606 por la cual el monasterio de Lourenzá se desprendía de todo derecho al tal foro a condición de que el conde de Lemos pagase una de renta 200 ducados, que aunque más elevada que los 2.000 maravedís antiguos seguía siendo simbólica en relación al principal ${ }^{40}$. Las cosas discurrieron de forma similar también en el conflicto que sostuvo con el monasterio de San Xulián de Samos. Después de haber éste puesto pleito en 1524 contra los condes de Lemos por el foro ya vaco de las aldeas de Balboa, Moldes y Dragonde entre otras, optó finalmente por renunciar a sus derechos a cambio de un juro perpetuo de 18.000 maravedís de renta anual según consta en la bula otorgada por el Papa Paulo III el 6 de febrero de $1543^{41}$. Por último, resulta igualmente sospechoso que la casa de Lemos lograra transformar su foro temporal sobre el coto de Bréamo en «feudo perpetuo» en el año 1569, justo cuando era prior del monasterio de San Miguel de Bréamo D. Dionis de Castro y Portugal ${ }^{42}$.

Por ultimo, cabe añadir que, en ocasiones, los nobles consiguieron forzar la conmutación de los foros a títulos de plena propiedad sin necesidad ni siquiera de llegar al extremo del enfrentamiento judicial; simplemente reclamándolo directamente como una especie de pago por los presuntos servicios y préstamos realizados en favor de las instituciones en cuestión. Eso es exactamente lo que ocurrió con el coto de Castellanos que el conde de Monterrei llevaba, en un inicio, en calidad de foro del monasterio de Porqueira, con cuyo prior se concertó posteriormente para que le fuera hecha donación de los derechos de propiedad sobre el mismo por «los muchos favores e mercedes» otorgados ${ }^{43}$.

\footnotetext{
${ }^{40}$ Montero Aróstegui, J., 1972, Historia y descripción de el Ferrol..., p. 412.

${ }^{41}$ Franco Silva, A., «El señorío de Villafranca de El Bierzo (siglos XIV y XV)», Boletín de la Real Academia de la Historia, 179, p. 48.

${ }^{42}$ Caja )M (2), MPL.

${ }^{43}$ Murguía, M., op. cit., p. 174
}

"CUADERNOS DE ESTUDIOS GALLEGOS", Tomo XLV, Fascículo 110, Santiago 1998. 
La labor de los Reyes Católicos en el seno de la Iglesia se saldó, pues, con la consolidación del reparto bajomedieval del dominio. Aunque la lucha no cesó por parte de la Iglesia, las soluciones fueron frecuentemente más favorables para los demandados que para los demandantes al encauzarse el conflicto por la vía de la acción judicial y del acuerdo compromisario en forma de feudos y foros. No es de extrañar por tanto que historiadores como M. Murguía hayan afirmado, y no refiriéndose precisamente a la hidalguía intermediaria moderna, que gracias a la figura del foro «hicieron los señores gallegos las más profundas heridas en las mesas capitulares y en la propiedad de los monasterios» al proporcionarles el relevo jurídico necesario para seguir disfrutando, sin ir contra derecho, de los dominios un día tomados por la fuerza.

Por lo que respecta al derecho de patronato, el resultado final sería similar a pesar de la especial atención que también le brindaron los Reyes Católicos. Ante el alarmante estado de ocupación en el que se encontraban los beneficios eclesiásticos gallegos, en el Concilio nacional celebrado en Sevilla en 1478 la Iglesia reclamó la urgente intervención de la Monarquía para poder poner remedio al estado de cosas creado ${ }^{44}$. La situación se presentaba, sin embargo, tan complicada que los Reyes Católicos optaron, después de su viaje a Galicia, por emprender una reforma radical de la Iglesia gallega. La bula «Inter curas multiplices», emitida a petición suya por Inocencio VIII el 27 de diciembre de 1487, ordenaba la devolución de los beneficios en los que se probara intromisión. Paralela y complementariamente a esa medida se establecía con igual fin la reordenación de los beneficios, su disgregación y nueva reunión, siempre que así conviniera ${ }^{45}$.

${ }^{44}$ El 3 de enero de 1466 el Papa Paulo III denunciaba la situación de despojo de las iglesias gallegas en los siguientes términos: «... sabido que los excesos denunciados y anatemizados por sus predecesores (...) seguían repitiéndose de la misma manera, y que sus sacrílegos y criminales autores (...) se conjuraban y confederaban (...) contra el clero, las iglesias, los lugares píos y la libertad eclesiástica; usurpaban diezmos, primicias y demás derechos eclesiásticos; negaban a los clérigos el pan, vino y demás cosas necesarias al sustento...»: cit. por E. Pardo de Guevara y Valdés, HIDALGUIA 27, p., 873.

${ }^{45}$ Para una relación pormenorizada del proceso de reforma puesto en marcha por los RRCC, véase, García Oro, J., 1971, Cisneros y la reforma del clero español en tiempos de los Reyes Católicos, Madrid.

"CUADERNOS DE ESTUDIOS GALLEGOS", Tomo XLV, Fascículo 110, Santiago 1998. 
Pero tampoco en este caso se logró adelantar nada, dada la fuerte oposición de los señores. Estos, para impedir que tales disposiciones se llevaran a efecto, no dudaron en recurrir a los monarcas pretendiendo llevar dichos beneficios por justos títulos y causas, y más concretamente, por presuntas donaciones regias hechas a sus antecesores en el proceso de reconquista frente al infiel. Precisamente, la razón de que no dispusieran de los testimonios documentales que así lo probasen era la propia antigüedad su adquisición, por lo que podían además alegar en su favor el beneficio de la posesión inmemorial. Todas estas pretensiones y exigencias las hicieron valer, además, recordando amenazadoramente a los monarcas que siendo por su condición «los mas principales del Reino», si se osaba privarlos de unos beneficios legítimos aun cuando sólo fuera por el derecho de posesión inmemorial, "se podría recrescentar algun escandalo entre ellos e los dhos. clerigos e que, por lo evitar se debe permitir e tolerar que las lleven, como hasta aqui... ${ }^{46}$.

Decididos los Reyes Católicos a no permitir que el equilibrio del sistema se rompiera, no dudaron en ceder ante la parte más fuerte y ordenaron de inmediato que se detuviesen las acciones emprendidas contra los patronos legos en tanto se estudiaba una solución al problema más sensible y respetuosa para con los intereses de la nobleza. El problema es que cualquiera de las soluciones de compromiso que se pudiera adoptar conllevaría siempre el menoscabo de la justicia de la que la Iglesia era acreedora. La vía finalmente propuesta por los monarcas, decantándose por el respeto de aquellos beneficios que llevasen cuarenta años en poder de legos, supuso una auténtica capitulación. Conllevó el sacrificio prácticamente sin paliativos de unos beneficios e intereses materiales que la Iglesia tenía derecho a recuperar en su integridad. Aunque la bula emitida por Alejandro VI el 27 de julio de 1493 dio cierto carácter de transitoriedad a la sanción propuesta por los monarcas, al someter esos beneficios a una investigación judicial, no se puede tampoco olvidar que las investigaciones tendrían que hacerse de forma particularizada e individualizada, y siempre por los cauces de la justicia ordinaria.

De capitulación se puede también hablar en el tema de los beneficios que los señores habían obtenido de manos de los reyes por juro de here-

${ }^{46}$ Ibidem, p. 75.

"CUADERNOS DE ESTUDIOS GALLEGOS", Tomo XLV, Fascículo 110, Santiago 1998. 
dad. En su amplio abanico de buenas intenciones, los Reyes Católicos se decidieron a revocar esas cesiones en las Cortes de Toledo. Pero, de nuevo, las presiones que de inmediato ejercieron las casas nobles les obligaron a prorrogar su aplicación hasta el final de su reinado ${ }^{47}$. La medida quedaba así en letra muerta, ya que no había medios legales de hacer cumplir esos dictados a los monarcas que en el futuro les sucedieran. En ese sentido, resulta muy ilustrativo de la conciencia que se consolidó en el Estado de la primera Edad Moderna sobre cuál debía ser la política de la monarquía en este terreno -el más puro respeto a la situación creadael hecho de que en los expedientes de venta de señoríos de la Iglesia -autorizados por Paulo III en su Breve aclaratoria del 5 de junio de 1548se incluyesen también este tipo de beneficios: diezmos, primicias y presentaciones ${ }^{48}$.

Todo parece indicar, por lo tanto, que el proceso de recuperación de beneficios quedó reducido en la práctica a una sucesión de pleitos inacabables, muy costosos y escasamente eficaces. A comienzos del siglo XVII, por ejemplo, el monasterio de San Martín Pinario gozaba, siempre según el testimonio de don Gerónimo del Hoyo, solamente de 300 beneficios de los más de 600 que originariamente solía percibir ${ }^{49}$. Pero es que, además, todavía a comienzos del siglo XIX este tipo de prebendas tenían un peso notable en buena parte de los dominios de la nobleza bajomedieval gallega.

Es cierto, efectivamente, que según los datos del Catastro de Ensenada el $90 \%$ de los diezmos era percibido por las propias instituciones eclesiásticas $^{50}$. Tradicionalmente, de hecho, se restó importancia a este capítulo de ingresos en el haber de los señores legos ${ }^{51}$. Pero si se desglosa su

${ }^{47}$ Véase, Morán Martín, R., 1986, El señorío de Benameijí. Su origen y evolución en el siglo XVI, Córdoba, p. 205.

${ }^{48}$ Ibidem, p. 133.

${ }^{49}$ Gerónimo del Hoyo, op. cit., p. 61.

${ }^{50}$ Véase, Eiras Roel, A., 1977, Las fuentes y los métodos..., Santiago, pp. 26-27; Saavedra, P., 1988, «Aportación al estudio de las rentas provinciales de la Galicia del Antiguo Régimen», en Espacio. Tiempo. Historia Moderna, 4, p. 475.

${ }^{51}$ Sólo desde finales de los años 80 se empezó a llamar la atención sobre la importancia que este tipo de ingresos podían llegar a adquirir en las casas de la alta nobleza. Véase, Saavedra, P., 1990, op. cit.; y Baz Vicente, M ${ }^{\text {a }}$ Jesús, 1991, op. cit.; Rey Castelao, O., 1993, «El reparto social del diezmo en Galicia», en Obradoiro de $H^{a}$ Moderna, I.

"CUADERNOS DE ESTUDIOS GALLEGOS", Tomo XLV, Fascículo 110, Santiago 1998. 
distribución en el espacio, la realidad que resulta ya no deja lugar a la misma contundencia. Mientras que en la provincia de Ourense, por ejemplo, el volumen de diezmos en poder de legos estaba bajo mínimos, con tan sólo un 0,2\%, en la provincia de Betanzos llegaba hasta el $27 \%$ y en la de A Coruña al 24,3\%. Pero aún hay más, en el haber patrimonial de algunos de los primeros títulos gallegos figuraba todavía a comienzos del siglo XIX un alto número de patronatos y de sincuras, a pesar de las cesiones $^{52}$ y permutas ${ }^{53}$ de que habían sido objeto en la Edad Moderna ${ }^{54}$.

En los dominios procedentes de los Mariñas, Andrade y Ulloa la fiscalidad eclesiástica se presenta como una fuente de ingresos de primera magnitud a finales del Antiguo Régimen. Además de presentar los curatos, los señores podían participar, en su calidad de patrones, en el beneficio de los diezmos así como en el arriendo o aforo de los diestrales en una proporción que podía ir desde una cuarta parte hasta la totalidad de los mismos. En el estado de Ulloa, por ejemplo, la renta decimal que cobraban los condes de Monterrei suponía a mediados del siglo XVIII en torno al $70 \%$ de los ingresos totales de la mayordomía ${ }^{55}$; y en la jurisdicción y estado de Cambados la renta de las sincuras era el ingreso más sustancioso según el testimonio del administrador de esta mayordomía a comienzos del XIX ${ }^{56}$. La importancia de este tipo de ingresos queda, por último, puesta de manifiesto en la importante conflictividad que rodeó a la participación de los Condes de Monterrei en los diezmos de sus sincuras. En los apeos del siglo XVII del estado de Ulloa y, sobre todo, en el de Cambados puede decirse que el conflicto en torno a los diezmos es prácticamente la única nota disonante.

${ }^{52}$ En los dominios de la casa de Andrade podríamos mencionar la donación hecha en favor del monasterio de Sta $\mathrm{M}^{\mathrm{a}}$ de la Gracia de Pontedeume de las sincuras recibidas por concesión de León X: Véase Vaamonde Lores, C., 1917, op. cit., p. 82.

${ }^{53}$ Por poner un ejemplo, el coto de Millán, en tierra de Lemos, se integró en los mayorazgos de esta casa a través de una permuta realizada en 1619 con el monasterio de S. Martín Pinario, que recibe a cambio precisamente la sincura de Sta $\mathrm{M}^{\mathrm{a}}$ de Merza, en el coto de Carboeiro: Pleito 1.459/3, AHRG.

${ }^{54}$ Hasta en un total de 59 parroquias figuraba la casa de Andrade como patrono y/o partícipe de los beneficios de las sincuras: «Certificación de la Declaración de Títulos» de sincuras realizada a partir de la Real Orden de 24 de octubre de 1853, MPL.

${ }^{55}$ Relación de arriendos de los años 1733, 1744 y 1747. Pleito 13316/19, AHRG.

${ }^{56}$ Misiva de 24 de junio de 1825, Caja 155-157, Hacienda, AHPOR. 
De todos modos, no por eso puede despreciarse el amplio derecho de patronato que tanto Lemos como Monterrei lograron consolidar; sólo en la diócesis de Lugo sus titulares eran patronos en unas 134 feligresías $^{71}$. $\mathrm{Si}$ algo pone de manifiesto la ofensiva que llevaron a cabo los señores sobre este tipo de prebendas después de las guerras Hirmandiñas, eso es la extraordinaria utilidad que tenía el derecho del patronato a la hora de asegurarse los señores el deseable ejercicio de sus derechos señoriales, siempre contestados por los pueblos. Fue precisamente ese interés el que llevó a Fray Simón a aconsejar a las monjas de San Paio que, en pro de una mayor explotación de sus patrimonios, «no dejaren perder las presentaciones, que importaban mucho a la autoridad de la casa» ${ }^{72}$; o el que llevó a obispos y clérigos a no cejar en su empeño de recuperar esos mismos derechos en los dos primeros siglos de la modernidad, a juzgar por el creciente número de pleitos entablados desde esas dos instancias contra los titulares de las casas objeto de este estudio, y en especial contra la de Andrade. En este caso intervino, al margen ya del origen fraudulento de muchas de esas sincuras y de la ineficacia de la estrategia restauradora diseñada por la nueva Monarquía ${ }^{73}$, lo gravoso que en ocasiones llegó a resultar la institución del patronato al conseguir sus titulares ir desvinculándose, incluso con el visto bueno de los tribunales reales de justicia, de las cargas que le eran inherentes ${ }^{74}$, contribuyendo así a mantener alto el nivel de tensión hasta el final del Antiguo Régimen.

${ }^{71}$ Sobre un total de 637 feligresías, 354 estaban fuera del concurso general y de la libre propuesta del obispo y nombramiento de la Corona por ser de legos. Véase, Garrote Martín, A., op. cit., apéndice.

${ }^{72}$ Colombás, G.M., op. cit., p. 149.

${ }^{73}$ Las casas nobiliarias pudieron defenderse con bastante eficacia contando con el beneficio de una prescripción rebajada ya a 40 años por los propios RRCC. En su defensa frente al monasterio de Vilar de Donas, por ejemplo, el Conde de Monterrei esgrimía la prescripción de su estado posesorio en los siguientes términos: «...el transcurso del tiempo tan luengo abastava, non solamente para la dha. posesion, pero tanbien para prescribir qualquier dro. a la propiedad e sennorio»: citado por Novo Cazón, J.L., op. cit.

${ }^{74}$ Las quejas en los libros de visitas sobre el mal estado de las iglesias, así como los pleitos provocados por la indigencia en la que en ocasiones se hallaban los curas -previas solicitudes no atendidas para el aumento de los beneficios del curato- así lo dejan ver. La misma casa de Monterrei fue absuelta por la Real Audiencia de Galicia de la obligación de costear las necesidades de mantenimiento de las iglesias de su patronato en la dicócesis de Ourense, según noticias del administrador general a la Comisión de Estados Secuestra-

"CUADERNOS DE ESTUDIOS GALLEGOS", Tomo XLV, Fascículo 110, Santiago 1998. 
A este respecto es muy ilustrativo el relevo que se produce entre las instituciones eclesiásticas demandantes de las casas de Lemos, Andrade y Monterrei. Mientras que entre los miembros del clero secular en el siglo XVI figuran obispos y cabildos, en el XVII los conflictos se limitan prácticamente a los clérigos rurales ${ }^{75}$; y lo que aún es más significativo, desengañados dichos clérigos de las expectativas de justicia creadas en su día, se irían alejando del recurso a los tribunales para intentar incrementar su participación en los beneficios del curato por la vía de la acción sobre el terreno aprovechando el absentismo de sus titulares, la lejanía y falta de celo de sus factores, así como la complicidad siempre colaboracionista de los vecinos ${ }^{76}$. Casas como las de Lemos, Andrade y Monterrei

dos a comienzos del siglo XIX (Caja 1097, Fondo Hacienda, AHPOR). Y es que como señala Garrote Martín (op. cit., p. 21), el problema tenía difícil solución en Galicia por cuanto al carecer «la inmensa mayoría de los patronos de escritura originaria de fundación», apoyándose «únicamente en el estado posesorio» que la ley reconocía, no resulta admisible que «los tribunales de justicia estén facultados para imponer una obligación cuando no consta la raíz y fundamento de ella». Veamos por su parte lo que opinaba el administrador general de los estados de Monterrei en 1815: «En diferentes parrochias del obispado de Lugo y del Arzobispado de Santiago en que (...) (se) percibe sincura ó porciones decimales siempre sus poseedores han concurrido á los gastos de la reedificación ó reparación de las Yglesias con proporcion á la parte de Diezmos que llevan; pero nunca he visto que se haya hecho igual solicitud en alguna de las Yglesias del Obispado de Orense porque en ninguna de ellas hay este derecho de sincuras (...). Es cierto que he oido decir fecuentemente y con especialidad en el Obispado de Lugo, que la construcción o reparacion de la capilla mayor de una Yglesia es de cargo del patrono; pero sea que esta opinión tenga por fundamento alguna constitución sinodal, o que tenga otro origen parece que no debe tener lugar sino quando los caudales propios de la Yglesia estan agotados».

${ }^{75}$ La casa de Andrade se enfrentó en el siglo XVI a los curas de Grandal y Doroña, y en el XVII, a los de Nogueira, Coiro, Deza, Nos, Bandoxa y Pruzos, con sus respectivos anejos, según puede constatarse en los pleitos conservados en el AHRG. En cuanto a la casa de Monterrei, se enfrentó en el siglo XVI con los Cabildos de Ourense y Lugo, y en el XVII con los curas de Pidre, Loureda, Ambreixo y Amoexa por el estado de Ulloa, y con el conjunto de los del estado de Cambados.

${ }^{76}$ La pura y simple intromisión, cobrando parte de los diezmos que correspondía a la sincura; la pretensión de tener derecho a cobrar el diezmo entero de todos los herederos del que un día había sido el mayor dezmero por derecho del excusado, aun cuando ya se había dividido su patrimonio (pleitos $1.43 / 32$ y 2.133/51, AHRG); o incluso la pretensión de cobrar el diezmo de los colonos del mayor dezmero cuando, según defendían los señores, el excusado se aplicaba sólo sobre los bienes que el dezmero llevaba por su propia cuenta (pleito 518/2); el negar el derecho del patrono con motivo de estivadas, cierres o nuevos cultivos como el de la patata, etc.

"CUADERNOS DE ESTUDIOS GALLEGOS", Tomo XLV, Fascículo 110, Santiago 1998. 
acabaron pasando, así, de demandadas a demandantes en la defensa de sus presuntos derechos -aun cuando fuera simplemente por prescripciónfrente a las intrusiones violentas de los clérigos que perturbaban su posesión, como la llevada a cabo a fines del siglo XVII en la tierra de Deza por el clérigo Asorey, que logró que otros correligionarios suyos de la tierra le acompañasen armados «con lanzas, espadas y otras armas» a la era del conde para exigir el diezmo allí reunido ${ }^{77}$. Los derechos de patronato de los señores habían adquirido tales visos de legitimidad que el recurso a la justicia lo terminaron limitando los clérigos prácticamente a los casos de incumplimiento de las obligaciones a las que en contrapartida habían quedado vinculados los patronos por el derecho común ${ }^{78}$.

\section{3.- LAS PREBENDAS ECLESIÁSTICAS DE LA NOBLEZA EN EL MARCO LIBERAL}

La gran sensibilidad de que dio muestras repetidas la legislación liberal para con los intereses de las casas nobiliarias se repite una vez más con aquellas prebendas de procedencia eclesiástica. Ni la abolición de los señoríos ni la desamortización les impidió seguir en posesión de los dominios que llevaban en concepto de feudo. En las hijuelas particionales de la casa de Alba siguen, por ejemplo, dominios como los de Cambados y Aveancos a pesar de haber tenido que pasar todo el patrimonio señorial de los Monterrei por un juicio de reversión ${ }^{79}$. Los derechos de posesión

\footnotetext{
${ }^{77}$ Pleito 1442/11, AHRG.

${ }^{78} \mathrm{El}$ enfrentamiento que en 1625 protagonizó el cura de Cambados con la casa de Monterrei se debía, entre otros factores, a la exigencia por parte de aquel de que dicha casa corriese con el pago de la «fábrica de galeones» concedida por S.M. sobre los frutos de los curatos ya que era aquella quien en realidad los llevaba por vía de patronato. Frente a ello, los condes de Monterrei solicitan que se les exima de tal carga amparándose en el hecho de que la sincura siempre estaba exenta de pagos tales como el subsidio diezmero, el excusado, etc, y máxime en un caso como éste en que su derecho a la sincura era por feudo de los comendadores de Malta: pleito 2.133/51, AHRG.

${ }^{79} \mathrm{~A}$ raíz de la muerte sin descendencia de la duquesa Cayetana en 1802 los dominios de Monterrei fueron secuestrados por la Corona para someterlos al juicio de reversión que venían exigiendo los jurisdiccionales del sur de la provincia de Ourense. Véase, Baz Vicente, $\mathrm{M}^{\mathrm{a}}$ Jesús, op. cit.
} 
adquiridos por la nobleza fueron en todo momento respetados, de manera que cuando las prebendas de naturaleza fiscal, como es el caso del diezmo, hubieron de ser abolidos por el nuevo régimen se les reconoció el derecho a una indemnización.

La construcción del régimen liberal conllevaba una reforma en el plano fiscal. Se imponía la uniformización y la racionalización del sistema impositivo, y con ello la eliminación de los mecanismos fiscales de carácter no estrictamente público, toda vez que los particularismos ya no tenían cabida dentro del régimen liberal. Los diezmos entraban de lleno en el saco de las figuras fiscales llamadas a desaparecer. Como señaló Mendizábal, haciendo referencia a los vicios de esta contribución en su «Memoria sobre el sistema actual de diezmos», ésta era una carga «desigual y arbitraria en su cuota, arbitraria también, y con frecuencia inhumana, en el modo de percibirla, e incompatible con un buen sistema de Hacienda ${ }^{80}$. Sin embargo, al igual que sucedió en otros terrenos, el desmantelamiento del Antiguo Régimen fue también aquí bastante lento dada la urgencia de los recursos financieros de que precisaba la hacienda pública, y dada la oposición que protagonizaron los sectores directamente afectados ${ }^{81}$. No fue hasta el año 1837 cuando, después de algunas otras medidas parciales, se estableció por la ley de 16 de julio su percepción por el Estado en calidad de impuesto civil; y no fue hasta 1841 cuando se abolió definitivamente, por la ley de 13 de agosto, estipulándose para el sostenimiento del clero los derechos de estola, obras pías, celebraciones $\mathrm{y}$ beneficios eclesiásticos ${ }^{82}$.

El respetuoso legalismo que hasta entonces había dominado en la liquidación de otras muchas instituciones del Antiguo Régimen se hizo sentir también en esta ocasión. La nacionalización y posterior abolición de los diezmos se realizó con la contrapartida del reconocimiento y del respeto de los derechos que los perceptores legos tenían adquiridos, lo

\footnotetext{
${ }^{80}$ Citado por E. Canales, 1985, «Diezmos y revolución burguesa en España», en A. García Sanz y R. Garrabou, eds., Historia agraria de la España contemporánea, Barcelona, vol. I, p. 258.

${ }^{81}$ Sobre el debate abierto y los argumentos empleados a favor y en contra de la abolición decimal, véase, Canales, E., op. cit.

${ }^{82}$ Escriche, J., 1838-47, Diccionario razonado de legislación y jurisprudencia, Madrid, p. 6696.
}

"CUADERNOS DE ESTUDIOS GALLEGOS", Tomo XLV, Fascículo 110, Santiago 1998. 
que evidentemente conllevaba la indemnización de los mismos con cargo a los presupuestos del Estado, y ello, además, de forma prácticamente automática pues se obviaba el origen que en cada caso en particular pudieran tener esos presuntos derechos. La ley establecía, efectivamente, como uno de los requisitos para poder hacerlos efectivos la presentación de los títulos acreditativos. Pero en última instancia se admitía también la certificación de la inmemorial posesión, como de hecho ocurrió con los diezmos de los dominios de Andrade según hemos podido ver a partir de la certificación de la declaración de títulos de sincuras realizado con motivo de la R.O. de 24 de octubre de 1853 de cara a acceder a la indemnización prevista por la ley ${ }^{83}$. En ella se establecía que para reclamar la indemnización por diezmos legos era necesario acreditar su percepción en el decenio de 1827-36 (art. $1^{\circ}$ ) y presentar los títulos originales de propiedad, pero que en su defecto se reconocería cualquier otro testimonio fehaciente y, en última instancia, la prueba de la posesión inmemorial. Se establecen dos años como plazo máximo para su reclamación, de 20 de marzo del 46 a igual fecha del $48^{84}$, y la capitalización inicial se fija en un $3 \%$ con la rebaja pertinente por las obligaciones religiosas adquiridas por los legos. Su indemnización se efectuaría en deuda pública consolidada del $3 \%$ por sextas partes a partir del 1 de julio, y las cinco partes restantes en certificaciones que se canjearían por títulos en los momentos que se designase. Las certificaciones les serían admitidas para pago de los débitos que tuviesen pendientes con la administración -medias annatas, lanzas, etc.; y los títulos de deuda podrían ser utilizados en la compra de bienes nacionales del clero regular o secular en lugar de títulos del $4 \%$ y $5 \%$.

Para hacer efectiva esa indemnización, el proceso administrativo a recorrer tenía como primer paso la presentación de los títulos de propiedad de los diezmos. Estos, una vez instruidos los correspondientes expedientes, se enviaban a la «Junta de Certificaciones de títulos de partícipes legos en diezmos» de acuerdo con lo establecido por la R.O. de 24 de

\footnotetext{
83 «Copia de la liquidación de diezmos del Excmo. Sr. Duque de Berwick y alba Conde de Lemos por sus estados de Miraflores, Puentedeume, Moeche...», Caja )M 1/1, MPL.

${ }^{84}$ R. O. de 5 de julio de 1849, Colección Legislativa, vol. II.
} 
octubre de 1853. Una vez declarados «legítimos» y su titular «acreedor a ser indemnizado de los diezmos que percibía en las parroquias» correspondientes, se procedía entonces a su liquidación conforme a las normas establecidas en 1846: en primer lugar se realizaba el reconocimiento de los expedientes de certificación de los derechos de percepción en el decenio arriba mencionado; a continuación se requerían dos «testimonios de precios medios», los certificados del párroco y alcaldes acreditando que la casa no tenía carga piadosa de beneficencia alguna, y por último, las certificaciones expedidas por la administración de culto y clero del área correspondiente sobre la parte de diezmos que correspondía al titular lego en la anualidad de 1837-38.

La Real Orden de 20 de mayo de 1849 parecía destinada a hacer cumplir de forma efectiva la defensa de los intereses de la Hacienda Pública en materia de indemnización de diezmos prevista en el artículo $4^{\circ}$ de la Instrucción de 28 de mayo de $1847^{85}$. La Hacienda Pública tenía representación en los juicios y contenciosos entablados en los Consejos Provinciales y en el Consejo Real sobre la calificación de los derechos de los partícipes legos de acuerdo con lo establecido en el artículo $4^{\circ}$ de la ley de 20 de marzo de 1846. Pero ahora, además, se insta a esos representantes, los fiscales de las subdelegaciones de rentas de las provincias, a sostener con firmeza los intereses de la Hacienda Pública en las demandas que se entablasen en los consejos provinciales. Siempre que se presentase una demanda de indemnización habría que dar conocimiento a los fiscales para que éstos pudieran reclamar del Ministerio de Haciénda las instrucciones, documentos y datos que se considerasen necesarios para la defensa del fisco; y siguiendo en esa misma línea de fuerza, cada vez que recayese sentencia definitiva, los fiscales tendrían que poner el recurso de apelación que correspondiera ante el Consejo Real.

A juzgar por esas órdenes, parece que al final el proceso no iba a resultar tan fácil como en un principio se pudiera pensar. No fue así, sin embargo. Cuando en los últimos años de la década de los 60 se elaboró el inventario de los bienes de mayorazgo de la casa de Alba, una buena parte de las solicitudes de indemnización habían sido ya

${ }^{85}$ Colección Legislativa, vol. II.

"CUADERNOS DE ESTUDIOS GALLEGOS", Tomo XLV, Fascículo 110, Santiago 1998. 
atendidas ${ }^{86}$, y ello sin que hubiera supuesto mayor obstáculn.la falta de documentos acreditativos del origen de la gran mayoría de los diezmos, a juzgar por las pruebas testificales a las que hubo que recurrir en los dominios de Andrade según la documentación conservada ${ }^{87}$. Pero es que, además, no todo se redujo a aboliciones e indemnizaciones. La moderación que animaba la letra de la ley hizo posible que las casas mantuvieran también vigentes y efectivos algunos de sus privilegios, como fue el caso por ejemplo del derecho de patronato propiamente dicho. Efectivamente, podría aducirse en contra, que la prerrogativa con rendimiento económico directo, el censo de reconocimiento, fue abolido y que únicamente se preservó la condición de patronos de sus titulares. Pero, con todo, esa condición de patrono de una iglesia ni siquiera entonces quedó reducida a una mera titulación honorífica.

Para empezar, hasta bien entrado nuestro siglo los patronos siguieron presentando a los párrocos que se deberían hacer cargo de la vida «espiritual» de los fieles. Para ello, pudieron contar también con el favor de la legislación desvinculadora, que mantuvo al margen de la partición igualitaria y de la libre circulación los derechos anejos a los bienes del mayorazgo ${ }^{88}$, como en este caso el patronato. Semejante control sobre

\footnotetext{
${ }^{86}$ Hasta ese momento la casa de Alba había recibido el 71,5\% de las indemnizaciones a que tenía derecho por razón de diezmos de legos, 5.044.784,98 reales sobre un total de 7.054.884 rs: 3.410.077,66 rs. por las mayordomías de Miraflores y Pontedeume; $341.133,33$ rs. por la de Vilalba; $563.537,33$ rs. por la de Moeche; 130.500 rs. por diezmos varios cobrados en la villa de Monforte; 228.500 rs. por la mayordomía de Doncos; y $371.036,66$ rs. por la jurisdicción de Aveancos. Estaban todavía pendientes de indemnización un total, 2.010.100 rs: 921.300 rs. por los diezmos de las jurisdicciones de Ulloa y Monterroso; 334.000 rs. de la mayordomía de Cambados; y 754.800 rs. de la mayordomía de Deza. Fuente: «Inventario y evalúo general de todos los muebles é inmuebles, censos, rentas, derechos y demás que constituían los Estados de los mayorazgos y otros vínculos en que sucedió el Excelentísimo Sr. D. Santiago Luis Fitz-James Stuart Duque de Alba», PP. 31648-31651, AHPM.

${ }^{87}$ «Razón de los gastos causados en las informaciones dadas para acreditar el valor de $\operatorname{los}^{\bullet}$ diezmos y la inmemorial posesión de percibirlos por la casa del Exmo. Sr. Duque en sus estados de Puentedeume y Moeche», Caja )M 1/1, MPL.

${ }^{88}$ El artículo 13 de la ley de 11 de octubre de 1820 establece que los títulos y prerrogativas de honor sussistirían con el orden de sucesión establecido en las fundaciones de mayorazgo. A falta del documento fundacional se entendería con arreglo, bien al estado posesrio, bien al derecho común que regulaba los mayorazgos.
}

"CUADERNOS DE ESTUDIOS GALLEGOS", Tomo XLV, Fascículo 110, Santiago 1998. 
una autoridad tan próxima a los vecinos tuvo que revestir además mayor valor que nunca. Téngase en cuenta que la vulnerabilidad que tradicionalmente padecían estos dominios, por causa del absentismo de sus titulares, de la extraordinaria dispersión de las propiedades y de la fragmentación de las rentas forales que producían, se vio agravada en el siglo XIX por la desaparición de las justicias y demás autoridades señoriales. Su autoridad e intermediación iba a servir, de hecho, para mejorar el grado de ejecución de los derechos forales que mantuvieron los titulares de estos linajes.

La instrumentalización del derecho de presentación con miras a la defensa de los intereses materiales de las casas patronas había sido una constante en el Antiguo Régimen. Los señores se valían de la autoridad moral que tenían los curas, que ellos mismos nombraban, para aquietar los ánimos levantiscos de sus jurisdiccionales y foreros, siempre dispuestos a contestar las demandas de sus señores. Entre otros muchos testimonios podríamos mencionar la instrumentalización que se hizo de la promoción a los curatos mejores en el conflicto surgido en la segunda mitad del siglo XVIII en la jurisdicción de Vilalba por causa de los derechos vasalláticos que los condes de Lemos cobraban como herederos de los títulos de los Andrade. En la carta que el 7 de enero de 1775 se envía a uno de los curas puestos por la casa, el administrador en Monforte se expresa en los siguientes términos:

«...Pero según está el presente teatro, es preziso mober las voluntades con una virtud remota, por que save Vmd., que ya sea el moelle, ô las Pendolas de un Relox, son muy distantes de el, no obstante, su fuerza y su peso se les haze dar las horas, mobiendo antes muchisimas ruedas; Por esto mismo: Para que Vmd. consiga los dos fines que me propone, se haze forzoso, poner los medios adequados; y el primero que se me ofreze, y me parece el mexor, es el que (...) Vmrd. como hixo de vasallo, mayordomo de esta renta, y que está gozando ese veneficio de la casa, pasase a su frâ. y persuadiere a los de su familia, Parientes y conbezinos...».

Y continúa diciendo: «...en fin, si hubiera de dezirlo todo, no me llegava una resma de Papel; y Vmd. puede en esta ocasión, haziendo el de buen vasallo y capellan afecto, promober la paz y tranquilidad para los vasallos, y la atenzion de S. Exa. al buen oficio de Vmd. a quien 
procurará su Exc. premiar, no solo con la yguala ô encavezado que solicita para su casa, sino promobiendole de ese Curato al de San Fiz de Reymonde y aun a otro mexor en el pais que le quadre, quedando Vmd. establecido en la estimazión de S. Exc...» ${ }^{89}$.

Esa instrumentalización de las autoridades eclesiásticas no cambió en nada con el establecimiento del ordenamiento liberal, ni siquiera en fechas tan avanzadas como los inicios del siglo XX, cuando los campesinos ya protagonizan, bajo la dirección de ciertos sectores mesocráticos, una resistencia organizada y radical contra los derechos forales de los antiguos señores. Para entonces, dados los serios problemas que tenía una casa como la de Alba para seguir defendiendo en los tribunales sus derechos $^{90}$, se hubo de recurrir sistemáticamente a la influencia de los poderes fácticos: a los caciques de los pueblos, a los que se encomienda más que nunca antes la administración y defensa en los tribunales de los intereses de estas casas; a los jueces y altos cargos políticos, amigos de la casa, para que presionaran sobre los juzgados más reacios; $\mathrm{y}$, cómo no, a los curas de las poblaciones afectadas, contando en este caso con la garantía que les ofrecía la deuda contraída con la casa, cuando eran de su nombramiento, o, en su defecto, la posibilidad de promocionarlos a uno de sus más apetecidos curatos.

En 1904, por ejemplo, el administrador de Pontedeume propuso a la administración central en Madrid, ante el problema de obscurecimiento que tenían los foros de la parroquia de Serantes, que puesto que esa parroquia, como las restantes, era de nombramiento de la casa «debiera imponerse al que vaya presentado (...) la obligación de describir los foros que en su término disfruta su excia.», ya que con su autoridad sobre los parroquianos podría forzarlos a dar la información que estaban negando a

\footnotetext{
${ }^{89}$ Exp. 23911/26, AHRG.

${ }^{90}$ Entre otros factores habría que mencionar la pérdida de la documentación acreditativa de sus derechos forales a manos de los herederos de sus administradores, así como el desarrollo de un derecho civil novísimo que, junto con la fuerte presión que lograron ejercier los campesinos a través de sus acciones violentas y ya comunitarias, logró que los jueces se inhibieran cada vez más en los conflictos que las casas foristas les llevaban. Véase, Baz Vicente, M ${ }^{\mathrm{a}}$ Jesús, 1996, op. cit., pp. 346 y ss.
} 
los administradores y abogados de la casa. Aunque Alba rechazó por prudencia un uso tan evidénte de su prerrogativa aduciendo que siempre se había seguido el principio de optar por aquellas personas que fueran dignas del cargo «por su virtud», lo cierto es que acto seguido añadió que también «por su adhesión a la casa». Así, aunque desestimó la propuesta del administrador, aclaró de inmediato en relación a la persona que tendría que ocupar la vacante de este curato: que «tendríamos en cuenta si su proceder respondía a la gratitud debida al patrono. Vea V. por tanto indicarnos si al hacer la provisión de la vacante ofrece su recomendado las condiciones de moralidad y adhesión antes expresadas».

Otro ejemplo del papel desempeñado por los sacerdotes en los conflictos agraristas de comienzos del siglo XX y de la utilización que se hizo del privilegio del patronato lo tenemos en la feligresía de Sada. Después de una década de negociaciones frustradas con los parroquianos para que se avinieran a pagar la renta foral o, de lo contrario, a redimirla, sólo en 1916 se consiguió un acuerdo parcial para su liquidación. Pues bien, según la opinión del administrador, tales resultados se debían a la promoción para ese curato del Sr. Villanueva. Algunos meses antes de que se produjera la vacante, mientras estaba enfermo de gravedad el sacerdote que ocupaba el curato, el administrador Puente informó a la administración central sobre la oportunidad que se abría para la casa, aconsejándoles que el duque de Alba tuviera en cuenta el sacerdote que él indicase en su momento, pues de esa forma, decía, «algo se iría beneficiando la casa $»^{91}$. El efecto favorable de esa elección se habría dejado sentir también en la feligresía de Veigue, en la que por iguales fechas se abren nuevas perspectivas de solución al conflicto con los foreros, ya que, afirma el administrador, «por virtud de esto» (la promoción del señor Villanueva), «personas interesadas en ello se ven obligadas para conmigo $»^{92}$. Recuerda, de hecho, acto seguido a la central que el «Duque puede salvar sus compromisos con otros curatos de los muchos que tiene como el de S. Xulián de Ferrol», cuyo párroco estaba también grave. Este tipo de procedimientos estaba tan asumido que se llegó incluso a dar el caso de que gentes dis-

\footnotetext{
${ }^{91}$ Carta $\mathrm{n}^{\circ} 25$, de 4 de agosto de 1916. Caja 12A, MPL.

${ }^{92}$ Carta n $^{\circ}$ 30, 28 de nviembre de 1916. Caja 12 A, MPL.
} 
puestas a comprar rentas forales de las que la casa se quería desprender sometieron la operación a la condición de algún curato ${ }^{93}$.

Un ejemplo último de los apoyos más amplios que pudo recabar una casa como la de Alba en la defensa de sus intereses mediante la instrumentalización del derecho de presentación a los curatos lo tenemos en lo ocurrido en las tierras de Chantada. En torno al año 1914 la administración central dio orden de que se liquidaran de una vez por todas las rentas de la administración de Ulloa y Deza, pero los tiempos que corrían eran difíciles: crisis de subproducción, inflación, bloqueo de las remesas de la emigración por causa de la guerra y, como agravante, las «malas ideas» que según el testimonio del administrador habían penetrado también en aquellas gentes. Las redenciones fueron avanzando, pero sólo después de grandes esfuerzos y presiones. Ante las resistencias, el administrador de Pontedeume hubo de trasladarse a la misma Chantada en 1917 para operar sobre el terreno. Una vez allí, según él mismo relata, puesto que la justicia de la zona tenía mala fama, decidió ponerse en contacto primero con uno de los personajes de influencia de la zona, un tal D. Jesús Rodríguez Mangueira, probablemente para que intercediera ante los foreros sobre la conveniencia de la redención. La respuesta del Sr. R. Mangueira no pudo ser más positiva, ofreciéndole incluso su colaboración para cuantos asuntos tuviera la casa pendientes en los juzgados de la provincia de Ourense, donde parecía tener buenos contactos. ¿La razón de tanta generosidad? Simplemente, tal y como él mismo puso de manifiesto, la cuenta pendiente que tenía con Alba por haberle atendido algún tiempo atrás una recomendación suya para un curato de la misma ${ }^{94}$.

Además de esa prerrogativa de inestimable valía social, el mantenimiento del derecho de patronato en manos de legos dio pie a conservar algunos de los beneficios materiales anejos al mismo contando con la laxitud, en ocasiones escandalosa, con la que se ejecutó la ley. Con ello nos estamos refiriendo a la abolición del censo de reconocimiento de pa-

\footnotetext{
${ }^{93}$ Es el caso de los hermanos Díaz, que solicitan en 1916 la promoción al curato de Sada para uno de ellos. La casa de Alba no accedió a entregárselo a ellos por el compromiso que tenía adquirida la casa con el candidato del administrador, pero a cambio les prometió algún otro «curato de entrada». Carta nº, 4 de abril de 1916. Caja 12 A, MPL.

${ }^{94}$ Carta $\mathrm{n}^{\mathrm{o}} 1,5$ de enero de 1918, Caja 12A, MPL.
} 
tronato por la legislación desamortizadora ${ }^{95}$. El hecho de que en su forma clásica se redujese al pago de un censo fijo, que incluso en ocasiones se había visto conmutado a una cantidad en dinero, no resta interés a lo ocurrido con él en el proceso liberal, entre otras cosas porque, al margen ya de ofrecernos una ocasión nueva para confrontar la forma en que se saldó la revolución burguesa en España, no siempre su importancia nominal era tan reducida. Puesto que ese censo era con cargo a los bienes del beneficio curado, en algunos dominios revestía la forma de una parte proporcional bien a las tierras del beneficio bien a la renta foral que éstas produjeran, tal y como ocurría en los dominios de Andrade y Ulloa. Tanto en un caso como en el otro, la casa de Alba logró conservar esos derechos sobre la tierra como propios hasta la liquidación de estos dominios a comienzos de nuestro siglo. En el Inventario de la casa de Alba de 1870 así como en la Hijuela particional de 1904 figuraba un importante número de partidas de renta foral sobre tierras originarias de los iglesarios.

En los dominios originarios de los Biedma, como ya se dijo, la carga del patronato estaba reducida a un censo fijo. Su pago fue objeto de resistencias abiertas una vez iniciada la reforma. Según una misiva de 8 de enero de 1822, los curas de A Limia habían decidido cesar de pagar el derecho de patronato por cuanto por el decreto de Cortes de 29 de junio de 1820 los diezmos ya no iban a sus manos. A pesar de eso y de que la legislación liberal posterior solucionó el problema por la vía, en principio, de la abolición, en la praxis esos derechos pudieron mantenerse en vigor. En la antigua jurisdicción de Torre Portela, por ejemplo, el censo de reconocimiento de patronato fue asimilado a una renta foral, figurando como tal en los inventarios e hijuelas particionales de la casa.

${ }^{95}$ Concordato de 1851, artículo 36. Véase Garrote Martín, A., op. cit., p. 11.

"CUADERNOS DE ESTUdIOS GALLEGOS", Tomo XLV, Fascículo 110, Santiago 1998. 


\section{APÉNDICE.-PATRONATOS Y SINCURAS DE LAS CASAS DE LEMOS, ANDRADE Y MONTERREI (*)}

ANDRADE, jurisdicción de Miraflores

Sta. $\mathrm{M}^{\mathrm{a}}$ de Oleiros presentación insolidum y $3 / 4$ del diezmo menos un diezmero

San X. de Suñeiro presentación insolidum, 1/2 del diezmo de sus propiedades y $1 / 4$ de las restantes

San X. de Iñás presentación insolidum, 1/2 del diezmo excluido el mayor diezmero

San P. de Nos presentación insolidum, 1/2 del diezmo

San A. de Carnoedo presentación insolidum, 3/4 del diezmo menos 1 diezmero

San X. de Lubre presentación insolidum, 1/2 del diezmo

Sta. $\mathrm{M}^{\mathrm{a}}$ de Dexo $2 / 3$ del diezmo -menos diezmeros.

San X. de Serantes presentación insolidum, todo el diezmo excluidos dos diezmeros y el diezmo de malladizos de lin y orjo

Sta. Comba de Veigue presentación insolidum, sin diezmo

San C. de Maianca presentación insolidum (los 3/4 del diezmo

San M. de Dorneda fueron donados a las monjas de Sta Bárbara) presentación insolidum, 3/4 del diezmo menos un diezmero

Sta. $\mathrm{M}^{\mathrm{a}}$ de Guísamo 1/6 del diezmo menos un diezmero (por foro de San Martín Pinario)

Sta. E. de Liáns presentación insolidum, todo el diezmo menos 4 diezmeros

San X. de Mondego presentación insolidum, (los 3/4 del diezmo fueron donados a Sta. Bárbara)

Sta L. de Alfoz-Perillo $1 / 2$ de la presentación

San X. de Ouces presentación insolidum, 1,5/4 del diezmo

Sta. $M^{a}$ de Sada presentación insolidum, 2/3 del diezmo mayor y $1 / 2$ de las menudencias

San M. de Orto presentación insolidum, 1/3 de diezmos y primicias

Coto de Vilaboa . (en el pasado de la casa)

ANDRADE, Mariñas de Betanzos

Sta. $\mathbf{M}^{\mathrm{a}}$ de Pontellas 1/4 del diezmo -menos un diezmero- y del iglesario

"CUADERNOS DE ESTUDIOS GALLEGOS", Tomo XLV, Fascículo 110, Santiago 1998. 
Sta. $\mathbf{M}^{\mathrm{a}}$ de Rois 2/3 del diezmo -menos un diezmero- y del iglesario.

ANDRADE, jurisdicción de Parada

Santiago de Revoredo 7/15 de la presentación, 1/2 del diezmo -menos un diezmero y solteros- e iglesario

Santiago de Parada 7/15 de la presentación, 1/3 del diezmo menos un diezmero-e iglesario

Sta. $\mathrm{M}^{\mathrm{a}}$ de Bandoxa 7/15 de la presentación, 3/4 del diezmo y del iglesario, más las primicias

ANDRADE, jurisdicción de Pruzos

Sta $\mathrm{M}^{\mathrm{a}}$ de Verins 1/4 del diezmo más una renta del iglesario

San M. de Churio $1 / 2$ del diezmo -menos 1 diezmero- y del iglesario

San Lr. de Irixoa $1 / 4$ del diezmo -menos 1 diezmero-y del iglesario

San de Esperela 1/4 del diezmo más una renta del iglesario

ANDRADE, jurisdicçión de Pontedeume

San X. de Piñeiro 2/3 del diezmo - menos un diezmero

San X. de Magalofes $1 / 2$ del diezmo -menos un diezmero

San M. de Laraxe 2/3 del diezmo

San M. de Porto presentación insolidum, 2/3 del diezmo -menos un diezmero

Sta. $M^{\mathrm{a}}$ de Sillobre presentación insolidum, 3/4 del diezmo -menos un diezmero

San S. de Maniños presentación insolidum, 7/8 del diezmo

San V. de Meá $1 / 2$ del diezmo -menos un diezmero

Sta. $\mathrm{M}^{\mathrm{a}}$ de Centroña 2/3 del diezmo -menos un diezmero

San C. de Nogueirosa presentación insolidum, 2/3 del diezmo -menos un diezmero

San P. de Grandal presentación insolidum, 5/8 del diezmo menos un diezmero

Sta. $\mathrm{M}^{\mathrm{a}}$ de Doroña 2/3 del diezmo

San X. de Torres presentación insolidum

San C. de Guimil $1 / 2$ del diezmo

Santiago de Franza .................. 2/3 del diezmo

San C. de Muniferral ............... 5/12 del diezmo

San P. de Vilarramo ................. 3/4 del diezmo

Sta. $\mathrm{M}^{\mathrm{a}}$ de Castro 2/3 del diezmo 
ANDRADE, estado de Moeche (**)

Sta. $\mathbf{M}^{\mathrm{a}}$ de Naraío ................... participación en los diezmos

Igrexiafeita ............................ participación en los diezmos

Recemel .............................. participación en los diezmos

San P. de Ferreira .................... participación en los diezmóos

y Quinta de Lamas .................. participación en los diezmos

San X. de Moeche ................... participación en los diezmos

ANDRADE, Esmelle $(* *)$............ participación en los diezmos

ANDRADE, Trasancos $(* *)$........ participación en los diezmos

ANDRADE, Serantes $(* *)$........... participación en los diezmos

ANDRADE, jurisdicción de Vilalba (**)

San M. de Lanzós ................... participación en los diezmos

San M. de Belesar ................... participación en los diezmos

San X. de Alba ...................... participación en los diezmos

San X. de Mourence ............... participación en los diezmos

San M. de Noche .................... participación en los diezmos

San C. de Nete ........................ participación en los diezmos

San X. de Rioabeso ................ participación en los diezmos

LEMOS, jurisdicción de Moreda

San P. de Canabal .................. presentación insolidum y participación en los diezmos

Sta. $M^{a}$ de Vilaescura ............. presentación insolidum y participación en los diezmos

Sta. E. de Licín presentación insolidum y participación en los diezmos

LEMOS, jurisdicción del Couto Novo

San N. de Millán presentación insolidum

San V. de Pinol presentación insolidum

San X. de Santiago presentación insolidum

LEMOS, jurisdicción de Paradela

San M. de Paradela ................. presentación insolidum

San P. de Paradela ................... presentación insolidum

San Lr. de Suar ...................... presentación insolidum

San V. de Paradela .................. presentación insolidum

"CUADERNOS DE ESTUdIOS GALLEGOS", Tomo XLV, Fascículo 110, Santiago 1998. 
Sta. C. de Paradela presentación insolidum

Sta. $\mathrm{M}^{\mathrm{a}}$ de Vilaragunte presentación insolidum

Santiago de Andreade presentación insolidum

LEMOS, jurisdicción de Somoza Maior

Sta. B. de Bardaos presentación insolidum

Sta. X. de Bardaos presentación insolidum

San T. de Castelo . presentación insolidum

San M. de Vilademouros presentación insolidum

San C. de Cervela presentación insolidum

San X. de Noceda presentación insolidum

San P. de Cubela . presentación insolidum

San X. de Remesar presentación insolidum

San V. de Rubián presentación insolidum

San M. de Vilasouto . presentación insolidum

LEMOS, jurisdicción de Saviñao

San S. de Chave.

presentación insolidum

Sta. E. de Rebordaos presentación insolidum

San E. de Ribas de Miño presentación alterna (6 turnos)

San. S. de Piñeirón presentación alterna (6 turnos)

LEMOS, jurisdicción de Pobra do Brollón

San X. de Eixón presentación insolidum

San C. de Martín presentación alterna

Sta. M. de Pinel presentación insolidum

Santalla del Rei presentación alterna

LEMOS, jurisdicción de Castro Caldelas

San P. de Abeleda y anejos:

Pedrouzas, Fonteita,

Pedraza, Celeiros ...................... presentación alterna y carga fija

Sta. $\mathrm{M}^{\mathrm{a}}$ de Torbeo y anejos:

Mazaira y Vilardá . presentación insolidum y carga fija

San P. de Fitoiro presentación y carga fija.

LEMOS, couto de Melias

San M. de Melias renta fija

LEMOS, jurisdicción de Torre Portela

San T. de Morgade presentación y renta fija

San P. de Boado presentación y renta fija

"CUADERNOS DE ESTUDIOS GALLEGOS", Tomo XLV, Fascículo 110, Santiago 1998. 
San T. de Trandeiros presentación y renta fija

San P. de pena presentación y renta fija

Cortegada presentación y renta fija

San S. de Río Freixo ................ presentación y renta fija San M. de Abavides ................ presentación y renta fija San A. de Piñeira ................... presentación y renta fija San Pedro de Laroa ................ presentación y renta fija

LEMOS, jurisdicción de Calvos de Randín

San P. de Muiños presentación y renta fija

Sta. $\mathbf{M}^{\mathrm{a}}$ de Barrio presentación y renta fija

San S. de Prado presentación y renta fija

Santiago de Calvos presentación y renta fija

San P. de Fernadeiros presentación y renta fija

Ríoseco presentación y renta fija

San V. de Lobás presentación y renta fija

San M. de Feás presentación y renta fija

San X. de Randín presentación y renta fija

Santiago de Rubios presentación y renta fija

LEMOS, jurisdicción de Adai

San X. de Corgo presentación insolidum

San F. de Bergazo presentación insolidum

S. C. de Chamoso presentación insolidum

Santiago de Laxosa presentación alterna

Sta. $M^{a}$ de Cabreiros presentación alterna

Sta. $M^{a}$ de Manán de a. presentación alterna

San E. de Espasantes presentación insolidum

Santiago de Adai. presentación insolidum

Sta. $\mathbf{M}^{\mathrm{a}}$ de Piñeiro presentación insolidum

San C. de Fiolleda presentación alterna (3 turnos)

Sta. $\mathbf{M}^{\mathrm{a}}$ de Franqueán presentación alterna

LEMOS, jurisdicción de Pobra San Xulián

Sta. $\mathrm{M}^{\mathrm{a}} \mathrm{M}$. de Escoureda presentación alterna

San P. de Maceda presentación alterna

San X. de Muro presentación insolidum

Sta. $\mathbf{M}^{\mathrm{a}}$ de Vilaleo presentación alterna (3 turnos)

Santalla Alta . presentación alterna (3 turnos)

San X. de Traslisle presentación alterna (3 turnos)

Pobra de San Xulián presentación insolidum

Sta. $M^{a}$ de Vilafiz presentación insolidum

"CUADERNOS DE ESTUDIOS GALLEGOS", Tomo XLV, Fascículo 110, Santiago 1998. 
LEMOS, jurisdicción de Neira de Xusá

San X. de Arroxo presentación insolidum

San T. de Guimarei presentación insolidum

Sta. M. de Vilachambre ............ presentación insolidum

San P. de Laxes.... presentación alterna

San M. de Berselos presentación alterna

San X. de Lexo presentación insolidum

San P. de Ferreiros presentación insolidum

LEMOS, jurisdicción de Outeiro de Rei

Outeiro de Rei presentación insolidum

Sta. M. de Rábade presentación insolidum

San V. de Rábade presentación insolidum

LEMOS, jurisdicción de Sarria

Sta. $\mathrm{M}^{\mathrm{a}}$ de Corvelle presentación insolidum

San S. de Ferreiros presentación insolidum

San E. de Lousadela presentación insolidum

San P. de Ronfe presentación insolidum

San P. de Maside presentación insolidum

Sta. E. de Arxemil presentación insolidum

San P.F. de Reimondez presentación alterna

Sta. M. de Sarria presentación alterna $(2 / 3)$

San S. de Vilar de Sarria .......... presentación alterna (2/3)

San X. de Veiga presentación insolidum

Sta M. de Rubín presentación insolidum

Santiago de Veiga presentación insolidum

San S. de Mato presentación insolidum

San P. F. de Paradela presentación alterna

LEMOS, jurisdicción de Deza (***)

San C. de Pena presentación y participación en diezmos

Sta. $\mathrm{M}^{\mathrm{a}}$ de Noceda presentación alterna y participación en diezmos

San M. de Prado presentación y participación en diezmos

San X. de Botos presentación insolidum y participación en diezmos

San F. de Xesta presentación insolidum y participación en diezmos

Sta. E. de Losón presentación y participación en diezmos San A. de Val presentación y participación en diezmos

"CUADERNOS DE ESTUDIOS GALLEGOS", Tomo XLV, Fascículo 110, Santiago 1998. 
Santiag de Gresande . presentación altẹrna y participación en diezmos

San X. de Cristimil presentación alterna y participación en diezmos

Sta. Ma de Dozón presentación y participación en diezmos

San M. do Cello presentación y participación en diezmos

Santiago de Sello presentación y participación en diezmos

San ? de Busto . presentación y participación en diezmos

San R. das Maceiras presentación y participación en diezmos

San X. de Anzo presentación alterna y participación en diezmos

San E. de Barcia presentación insolidum y participación en diezmos

Santiago de Anseán .. presentación insolidum y participación en diezmos

San M. de Lalín presentación y participación en diezmos

Sta. E. de Donsión presentación y participación en diezmos

San M. de Goias presentación y participación en diezmos

Sta. E. de Prado .. presentación y participación en diezmos

San X. de Rosdís . presentación y participación en diezmos

Sta. $M^{a}$ de Filgueira presentación y participación en diezmos Sta $\mathrm{M}^{\mathrm{a}}$ de Oirós presentación y participación en diezmos

San A. de Monixas presentación y participación en diezmos Santiago de Catasós San X. de Vilanova . presentación y participación en diezmos presentación insolidum y participación en diezmos

San P. de Doade presentación y participación en diezmos

San P. de Lodeiro presentación y participación en diezmos

San M. de Bodaño presentación y participación en diezmos

San C. de Campsancos

Sta $\mathrm{M}^{\mathrm{a}}$ de Asorei . presentación y participación en diezmos

San Lr. de Vilatuxe presentación y participación en diezmos

Sta $\mathrm{M}^{\mathrm{a}}$ de Donramiro presentación y participación en diezmos presentación y participación en diezmos

MONTERREI, jurisdicción de Souto Bermudo (Riós y A Gudiña) (****) San E. de Trasestrada carga fija por patronato

San M. de Pentes carga fija por patronato

MONTERREI, jurisdicción de Rairiz da Veiga (****)

San de Zapeaus carga fija por patronato 
MONTERREI, jurisdicción de Espinoso $(* * * *)$

San M. de Espinoso ................. carga fija de dos ducados por derecho de patronato

MONTERREI, jurisdicción de Ulloa

Santiago de Curbián patrono insolidum, 1/3 del diezmo

San S. de Carballal ................. patrono insolidum, 1/2 del diezmo y foro del iglesario

San J. del Camino patrono insolidum, 1/2 del diezmo y foro del casar del iglesario

Sta. $\mathbf{M}^{\mathrm{a}}$ de Sambreixo patrono insolidum, 1/2 del diezmo y foro del casar del iglesario

San Cibrao patrono insolidum, 1/2 del diezmo

Sta. $\mathrm{M}^{\mathrm{a}}$ de Pidre patrono insolidum, 1/2 del diezmo

San J. de Repostería patrono insolidum, 1/2 del diezmo y foro del iglesario

Santiago de Cabana patrono insolidum, 1/2 del diezmo y foro de la mitad del iglesario

San P. de Pambre patrono insolidum, 1/2 del diezmo

San M. de Coence patrono insolidum, $1 / 2$ del diezmo

Santiago de Alba patrono insolidum, 1/2 del diezmo

Sta. $\mathbf{M}^{a}$ de Pedraza patrono insolidum, $1 / 2$ del diezmo

San C. de Gundin ................... patrono insolidum, 1/3 del diezmo

San Lr. de Pedraza ................. patrono insolidum, 1/3 del diezmo

Santiago de Bidoureda ............ patrono insolidum, 2/3 del diezmo

San P. de Villareda ................. patrono insolidum, 1/2 del diezmo

San T. de Palas de Rei ............ patrono insolidum, 1/2 del diezmo y foro del iglesario

San T. de Figueroa ................. patrono insolidum, 1/3 del diezmo

San J. de Laia ........................ patrono insolidum, 1/4? del diezmo y foro del iglesario

Sta. $\mathbf{M}^{\mathrm{a}}$ de Puxeda patrono insolidum, 1/2 del diezmo

San M. de Maceda patrono insolidum, 1/2 del diezmo y foro del iglesario

Sta. Ma Coiña patrono insolidum, 2/3 del diezmo

San J. do Mato patrono insolidum, 1/6 del diezmo

San V. de Ambreixo patrono insolidum, 2/3 del diezmo y foro de 2/3 del iglesario

San M. de Reimonde patrono insolidum, 1/2 del diezmo

San V. de Ulloa patrono insolidum, 1/2 del diezmo y foro del iglesario

"CUADERNOS DE ESTUdIOS GALLEGOS", Tomo XLV, Fascículo 110, Santiago 1998. 
San Mamede .......................... patrono insolidum, 1/4 del diezmo

San. M. de Vilaproupe ............ patrono insolidum, 2/3 del diezmo

San M. de Tajin?. ................... patrono insolidum, 1/2 del diezmo

San P. de Vilamba? ................. patrono insolidum, 1/2 del diezmo

San J. de Lodoso ..................... patrono insolidum, 1/2 del diezmo y foro del iglesario

Sta. $\mathrm{M}^{\mathrm{a}}$ de Fontecuberta .......... 1/2 del diezmo

San P. de Salaia ..................... 1/2 del diezmo

Santiago de Ligonde ............... 1/3 del diezmo

San M. de Berberros ................ 1/2 del diezmo

Santiago de Mosteiro............... 2/3 del diezmo

Sta. $\mathrm{M}^{\mathrm{a}}$ de Alvidron ................ 1/3 del diezmo y foro del iglesario

San J. de Santas .................... 1/3 del diezmo y foro del iglesario

Santiago de Lestedo................ 1/2 del diezmo y foro del iglesario

San A. de Orosa ..................... 1/2 del diezmo

MONTERREI, jurisdicción de Monterroso

Santiago de Soengas ............... patrono insolidum, 1/3 del diezmo

Sta. $\mathbf{M}^{\mathrm{a}}$ de Naron ................... patrono insolidum, 2/3 del diezmo

San C. de Velinde .................. patrono insolidum, 1/2 del diezmo

Sta. $\mathbf{M}^{\mathrm{a}}$ de Sucastro ............... patrono insolidum, 1/3 del diezmo

San C. de Ferreiros ................. patrono insolidum, 2/3 del diezmo

Sta. E. de Seteigrexas ............. patrono insolidum, 1/2 del diezmo

Labandelo y anejo ................... patrono insolidum, 1/2 del diezmo

Sta. $\mathbf{M}^{\mathrm{a}}$ Darada ....................... patrono insolidum, 1/4 del diezmo

San A. do Rial ....................... patrono insolidum, 1/2 del diezmo

San S. de Balboa .................... patrono insolidum, 1/2 del diezmo

Santiago Damoexa................. patrono insolidum, 1/2 del diezmo

Santalla de Santiso .................. patrono insolidum, 2/2 del diezmo

Sta. $M^{a}$ de Darcos ................... 1/3 del diezmo

San M. Cumbraos .................... 1/2 del diezmo

San S. de Sabadelle ................ 2/3 del diezmo

San A. de Villarbasin ............. 2/3 del diezmo

San A. de Frigal ...................... 1/3 del diezmo

San P. Darxiz ......................... 2/3 del diezmo

San J. de Insua ........................ 1/3 del diezmo

Santalla de Villar C ................ 1/3 del diezmo

San X. de Terrachá .................. 1/4 del diezmo

San M. Daguela ...................... 1/2 del diezmo

San P. dos Queixeiros ............. 1/2 del diezmo

"CUADERNOS DE ESTUDIOS GALLEGOS", Tomo XLV, Fascículo 110, Santiago 1998. 
MONTERREI, jurisdicción de Aveancos

San Juan de Bisantoña presentación insolidum, 1/6 del diezmo y foro del iglesario

San C. de Pezobres y sus tres anejos presentación insolidum, 1/4 del diezmo

Ponte Arcediago y anejo. presentación insolidum, $2 / 3$ del diezmo

S. de Lairiz y anejo. presentación insolidum, 1/3 del diezmo y foro del iglesario

San X. de Mourazos presentación insolidum, 1/5 del diezmo

Santiago de Vilouriz y sus anejos presentación insolidum, 1/2 del diezmo

San M. de Oleiros presentación insolidum, 2/3 del diezmo

San S. de Aveancos presentación insolidum, 1/3 del diezmo

San P. de Folladela presentación insolidum, 1/4 del diezmo y foro del iglesario

Sta. $\mathbf{M}^{\mathrm{a}}$ de Campos presentación insolidum, 1/4 del diezmo

San M. de Barreiro presentación insolidum, 1/3 del diezmo y foro del iglesario

San C. de Aveancos presentación insolidum, 1/4 del diezmo

San P. de Cumeiro presentación insolidum, 1/2 del diezmo

Sta. M. de Varazon presentación insolidum, 1/4 del diezmo

San E. de Pezobres presentación insolidum, 1/4 del diezmo

San T. de Mangueira presentación insolidum, 1/2 del diezmo

MONTERREI, jurisdicción de Augas Santas

San X. de Augas Santas ...... presentación insolidum, 2/3 del diezmo

San Salvador de Merlan ...... presentación insolidum, 2/3 del diezmo

San T. de Felpos ................. presentación insolidum, 1/3 del diezmo

San X. de Felpos ................ presentación insolidum, 2/3 del diezmo

Santiago de Guldrid ............. presentación insolidum, 1/2 del diezmo

San X. de Pregacion ............ presentación insolidum, 1/2 del diezmo y foro del iglesario

San C. de Narla .................. presentación insolidum, 1/2 del diezmo

San X. de Ruimil ................. 1/5 del diezmo

San Lr. de Vilamaior ........... 3/16 del diezmo y foro del iglesario

San M. de Vilamea .............. 1/2 del diezmo

San C. de Monte Meda ....... 1/2 del diezmo y foro de la sincura

Santalla de Padreda ............. 1/2 del diezmo y foro del iglesario

Sta. $\mathrm{M}^{\mathrm{a}}$ de Zolle ................. 3/4 del diezmo y foro del iglesario

"CUADERNOS DE ESTUDIOS GALLEGOS", Tomo XLV, Fascículo 110, Santiago 1998. 
(*) En este listado no figuran por razones evidentes todos los patronatos y sincuras que correspondían a dichas casas. Fuentes: Apeo de Miraflores (1679), MPL; Apeo de las Mariñas de Betanzos (1698), MPL; Padrón de la jurisdicción de Pruzos (1763), exp. 10204/30, AHRG; «Relazion, descripcion del estad de Lemos...» Lemos, caja 248-207, ADA; Padrón de la jurisdicción de Torre Portela (1613), expl. 9392/29, AHRG; «Demostración de sincuras de Torre Portela y Calvos de Randín (1841)», bloque 22/3, MPL; «Testimonio certificado de las rentas sincuras que el Esm ${ }^{\circ}$ Sor. Duque de Berwick y Alva (...) percibio en sus estados de Villalva, Doncos y Monforte en tdo el decenio de 1827 al de $1836 \ldots$.., bloque 7/26, MPL; «Libro que contiene razon de los pagos que se hacen en esta administracion general de Monterrey...» (1787), caja 53560, AHPOR; Apeos de las jurisdicciones de Ulloa, Monterrso, Aveancos y Augas Santas (1672), MPL; Catastro de Ensenada; Garrote Martín, A., op. cit., apéndice; G. del Hoyo, 1607, op. cit., apéndice.

(**) Las fuentes no aclaran si la casa tiene derecho de presentación, como tampoco la parte alícouta que le corresponde de los diezmos.

$(* * *)$ La fuente no aclara si la presentación es insolidum o compartida, como tampoco la alícuta de los diezmos que le corresponde a la casa.

$(* * * *)$ Las fuentes no aclaran si le corresponde a la casa el derecho de presentación. 